\title{
Physicochemical Control of Adult Stem Cell Differentiation: Shedding Light on Potential Molecular Mechanisms
}

\author{
Igor Titushkin, ${ }^{1}$ Shan Sun, ${ }^{1}$ Jennifer Shin, ${ }^{2}$ and Michael Cho' \\ ${ }^{1}$ Department of Bioengineering, University of Illinois, Chicago, IL 60607, USA \\ ${ }^{2}$ Departments of Mechanical Engineering and of Brain and Bioengineering, Korea Advanced Institute of Science and Technology, \\ 305-701 Daejeon, South Korea
}

Correspondence should be addressed to Michael Cho, mcho@uic.edu

Received 13 October 2009; Accepted 27 January 2010

Academic Editor: David Colin Hay

Copyright (c) 2010 Igor Titushkin et al. This is an open access article distributed under the Creative Commons Attribution License, which permits unrestricted use, distribution, and reproduction in any medium, provided the original work is properly cited.

\begin{abstract}
Realization of the exciting potential for stem-cell-based biomedical and therapeutic applications, including tissue engineering, requires an understanding of the cell-cell and cell-environment interactions. To this end, recent efforts have been focused on the manipulation of adult stem cell differentiation using inductive soluble factors, designing suitable mechanical environments, and applying noninvasive physical forces. Although each of these different approaches has been successfully applied to regulate stem cell differentiation, it would be of great interest and importance to integrate and optimally combine a few or all of the physicochemical differentiation cues to induce synergistic stem cell differentiation. Furthermore, elucidation of molecular mechanisms that mediate the effects of multiple differentiation cues will enable the researcher to better manipulate stem cell behavior and response.
\end{abstract}

\section{Introduction}

The multipotent adult stem or progenitor cells reside at restricted locations to allow continuation of the cycle of life [1]. These tissue-specific stem cells have been identified in the bone marrow [2], brain [3], skin [4], retina [5], pancreas [6], intestinal crypt [7], and liver [8] as well as in skeletal muscle [9]. Depending on the origin, these adult stem cells exhibit the potency to differentiate into multiple cell types. Adult stem cells from muscle, for instance, predominantly become myogenic or hematopoietic [10] while those from bone marrow are known to harbor hematopoietic, endothelial and mesenchymal (MSC) stem cells. MSCs derived from the bone marrow stroma are multipotent, hypoimmunogenic $[11,12]$, and proliferate freely in vitro to undergo selfrenewal and differentiation into multiple non-hematopoietic cell lineages such as chondrocytes, osteoblasts, adipocytes, and myoblasts, and cardiomyocytes [13], and neuronal cells [14-16]. This is attractive because, for example, unlike extraction of the neural stem cells or neural precursors that would require surgery, MSCs are relatively easy to isolate and differentiate into neuronal cells, and therefore may be useful for tissue engineering strategies to repair and regenerate connective and excitable tissues. Other tissues such as adipose tissue, periosteum and synovial tissue have been shown to contain cells with properties similar to those of stem cells. However, the limited life span and amount of cells as well as their heterogeneity pose difficulties in utilizing this particular cell population in the basic research and therapeutic applications [17-20].

Generally, stem cells have the unique property of selfrenewal without differentiation until and unless appropriate biological and physical signals are provided. In the context of tissue engineering, the idea of using stem cells offers numerous advantages. Unlike engineering tissue constructs with differentiated cells, the multipotent mesenchymal stem cells (MSCs) are hypoimminogenic, have higher proliferative capacity and provide excellent regenerative capability that will likely lead to desired integrity and functionality of the engineered tissue. Moreover, MSCs make it possible to engineer multifunctional tissue constructs and also can be differentiated into phenotyically and functionally diverse lineages (e.g., osteoblasts and neuronal cells). It is plausible that stem cell-based tissue implants can be designed for tissue formation and vascularization at the same time, which mimics typical physiological responses to tissue damage. 
Stem cell-based therapeutic application therefore appears quite attractive. However, a clearer understanding and adequate control of stem cell differentiation into tissuespecific lineages would first have to be firmly established. For example, development of the strategies to control stem cell behaviors and directing them to a specific lineage would require an understanding and manipulation of the cell-environment interactions. Determination of an optimal physicochemical microenvironment could lead to harvest the unique properties of the stem cells for self-renewal and tissue-specific differentiation that can be guided or perhaps directed by biochemical and physical cues. Rational approaches for stem cell-based engineering of functional tissues would then be realized and could be implemented, thus potentially overcoming the current challenges in regenerative medicine. The therapeutic applications of stem cells would undoubtedly be enhanced by an efficient differentiation protocol that could prescribe the phenotype. Upon implantation of an engineered tissue construct, it may also be plausible to intervene externally and regulate the fate of stem cells.

In this review paper, we will first illustrate that the soluble factors and external physical forces (i.e., physicochemical cues) have been combined, engineered and applied to induce synergistic MSC differentiation. We will next elucidate the potential mechanism(s) that mediate the MSC differentiation in response to the physicochemical cues. A detailed understanding of the lineage-dependent mechanisms would be expected to prescribe the MSC differentiation into specific tissue types using multiple cues.

\section{Synergistic MSC Differentiation}

There are at least three different techniques that have been utilized for MSC differentiation. First, the biological and pharmacological reagents (e.g., hormones) have been used to induce stem cell differentiation into bone cells [22-24], chondrogenic cells [25], adipogenic cells [26, 27], and even functional neuronal cells $[16,28-30]$. Further, MSCs have also been shown to differentiate into the myogenic lineage $[31,32]$. These recent advances in the MSC manipulation demonstrate that the multipotent stem cells are capable of differentiating into excitable and non-excitable tissue phenotypes. Second, the MSC differentiation may be regulated by mechanical cues, including changes in the cellular morphology [13,33] and matrix elasticity [34]. As the matrix stiffness increased, the focal adhesions could increase in size and also expression of the focal adhesion molecules. This is consistent with the finding that the cell adhesion of several distinctive types may be involved, including focal complexes, focal adhesion, and fibrillar adhesion [35]. The cells may utilize the crosstalk between the extracellular matrix and the cytoskeleton, likely mediated by integrins, to determine the adhesion type. Other environmental factors (e.g., oxygen tension) have also been incorporated to solicit synergistic stem cell differentiation [36]. Third, external mechanical and electrical forces have been applied to regulate MSC differentiation. For example, while a cyclic mechanical stretch can enhance bone formation [37-42], various types of shear stress can synergistically enhance MSC osteodifferentiation [43-47]. Low intensity ultrasound, another form of mechanical stress, has also shown to enhance the chondrogenic differentiation $[48,49]$. A recent study by Haudenschild et al. [50] reported the ability of MSCs to distinguish between dynamic tensile and compressive loading by regulating distinct gene expression patterns. While dynamic tensile stresses induce both the fibroblastic and osteogenic markers, a compression upregulated the chondrogenic gene expressions. Moreover, our laboratory has recently found that an electrical stimulation facilitates osteodifferentiation [24], suggesting that physical stimuli can induce synergetic effects. Since the electrical and mechanical nature of the cell is now well established, we suggested that cellular and molecular responses to external physical stimuli would be cast more appropriately as electromechanical responses [51]. Because there appear to be several physicochemical differentiation cues that promote stem cell differentiation, strategies to optimize these cues to facilitate or interfere with the intended fate of stem cells may be highly significant for regenerative tissue engineering and also in general stem cell biology. Optimization of at least three known cues would have to be determined based on multifactorial experimental design, requiring sophisticated statistical analyses. However, the focus of this review is to illustrate synergistic stem cell differentiation in response to a combination of soluble factors and externally applied physical stimuli, which may additively or synergistically facilitate the intended MSC differentiation. For this purpose, a simplified definition may be used instead. While additive differentiation implies effects (e.g., quantifiable tissue-specific markers) produced by multiple cues should be the same as the sum of each cue used alone, synergistic differentiation would imply greater than the sum of effects produced by each cue when a combination of the physicochemical cues is applied. For example, a combination of soluble factors and an electrical stimulation induces synergistic osteodifferentiation, while the use of an electrical stimulation alone fails to differentiate MSCs [24]. Synergistic interaction may also lead to accelerate the pace at which the intended stem cell differentiation proceeds.

Strategies to optimize various differentiation cues to facilitate and interfere with the intended fate of stem cells may be highly significant for regenerative tissue engineering and also in general stem cell biology. In addition to demonstrating synergistic stem cell differentiation in response to a combination of soluble factors and externally applied physical stimuli, elucidation of the potential coupling mechanisms would have to be studied. Both mechanical and electrical stimulation has been applied separately and combined with soluble factors to facilitate MSC differentiation. For example, recent studies show that, when vascular endothelial growth factor (VEGF) and a shear stress are used in a combinatorial manner, synergistic differentiation of endothelial progenitor cells into endothelial cells may be accomplished [52], and synergistic chondrogenic differentiation of MSCs achieved by combining TGF- $\beta 3$ and a hydraulic pressure [53]. A combination of fluid shear stress and bone-like extracellular matrix, made of titanium (Ti) fiber mesh discs, both 
in the presence or absence of osteogenic dexamethasone synergistically enhance the osteodifferentitation of MSCs [54]. Synergistic effects are also observed when a cyclic strain is combined with dexamethasone to enhance the osteogenic commitment of human MSCs [55]. Alternatively, soluble factors combined with an electrical stimulation induce synergistic osteodifferentiation, while the use of the electrical stimulation alone fails to differentiate MSCs toward osteoblasts [24]. Varying the modality of electrical stimulation, pulsatile biphasic electric field is now shown to enhance MSC proliferation and upregulate the differentiation related genes [56], and an sinusoidal electrical stimulus $(100 \mathrm{mV}$ peak-to-peak at $4,000 \mathrm{~Hz})$ appears to induce differentiation of rat PC12 and blastocyst-derived murine embryonic stem cells toward the neuronal lineage [57].

\section{Elucidation of Mechanisms}

Of potential mechanisms that might mediate the effects of multiple differentiation cues, we will focus on the three recent but likely mechanisms that have been carefully studied and documented. First, calcium dynamics in MSCs undergo noticeable changes that are lineage-dependent, suggesting that calcium plays a critical role in cell differentiation [58$60]$ and could be used as a modulator for MSC differentiation. Second, mitogen-activated protein (MAP) kinasedependent signaling has emerged as a potent regulator of stem cell commitment and differentiation [61, 62]. Since mechanotransduction is likely associated with MAP kinase signaling, the potential coupling mechanisms to the MAP kinase signaling by the differentiation cues could offer beneficial strategies for tissue engineering. Third, cellular biomechanical remodeling shows noticeably remarkable alterations that are also lineage-dependent. Moreover, a close correlation or interdependence between the $\left[\mathrm{Ca}^{2+}\right]_{i}$ and cytoskeletal reorganization is well known, established, and accepted, although the effects of altered and modulated $\left[\mathrm{Ca}^{2+}\right]_{i}$ oscillation on the cellular mechanics are yet to be fully elucidated. It is interesting to note that, in response to osteogenic soluble factors or physical stimuli, the human MSC cellular mechanics become indistinguishable from that of osteoblasts in about 10 days [63], and the maximal changes in the $\mathrm{Ca}^{2+}$ dynamics also takes about 14 days [24]. This may suggest that the biomechanical remodeling could precede the cellular and molecular identities of stem cell-derived osteoblasts, and that the microfilament-based biomechanical remodeling and $\left[\mathrm{Ca}^{2+}\right]_{i}$ oscillation are intimately connected. MSCs can differentiate down the lineages that are mechanically at the opposite ends of the spectrum; mechanically strong osteoblasts versus soft neuronal cells. There is no doubt that MSCs will have to reorganize their cytoskeleton and membrane to comply with the intended differentiation. While methodologies are readily available to characterize changes in the calcium dynamics and the biochemical properties, more subtle questions yet to be fully answered include whether changes are simply a consequence of MSC differentiation or perhaps a critical determinant to prescribe MSC differentiation.
3.1. Role of Calcium in Cell Differentiation. Calcium $\left(\mathrm{Ca}^{2+}\right)$ is a ubiquitous second messenger and represents one of the most important biological signals [64]. The intracellular $\mathrm{Ca}^{2+}$ regulates important cellular and molecular processes such as proliferation, differentiation, cell biomechanics, cytoskeletal reorganization, gene expression and metabolism $[21,65,66]$. Among many cell types, stem cells exhibit robust calcium activities and appear to undergo $\left[\mathrm{Ca}^{2+}\right]_{i}$ oscillation. Transient elevations in free cytosolic $\mathrm{Ca}^{2+}$ concentration (i.e., $\left[\mathrm{Ca}^{2+}\right]_{i}$ ) referred to as spikes are a nearly universal mode of signaling in both excitable and non-excitable cells $[67,68]$. While the role of oscillatory $\mathrm{Ca}^{2+}$ signals has been extensively studied but not yet fully understood, it is evident that spatial and temporal patterns of $\mathrm{Ca}^{2+}$ dynamics (e.g., spiking amplitude and frequency, and spatial distribution) are important characteristics of cellular regulatory pathways. $\left[\mathrm{Ca}^{2+}\right]_{i}$ oscillations are likely mediated by at least several cell type-dependent $\mathrm{Ca}^{2+}$ influx/efflux pathways. First, $\mathrm{Ca}^{2+}$ entry across the plasma membrane can be mediated via voltage-operated $\mathrm{Ca}^{2+}$ channels, stretchactivated cation channels, and agonist-dependent channels $[69,70]$. Second, $\mathrm{Ca}^{2+}$ release from intracellular stores (e.g. endoplasmic and sarcoplasmic reticulum, mitochondria) can be controlled by inositol 1,4,5-triphosphate $\left(\mathrm{IP}_{3}\right)$-gated channels and ryanodine receptors [71]. Third, the excess $\mathrm{Ca}^{2+}$ is pumped back from cytosol to internal stores or extruded to extracellular medium by $\mathrm{Ca}^{2+}$-ATPase pumps [72]. While biochemical cascades, molecular and cellular interactions, and gene expression profiles can be controlled by altered intracellular $\mathrm{Ca}^{2+}$ dynamics, intracellular calcium activities themselves can be regulated by a variety of external physical stimuli, including electromechanical stimulation and substrate rigidity [73].

Calcium is also recognized to play a critical role in cell differentiation. More specifically, spontaneous $\left[\mathrm{Ca}^{2+}\right]_{i}$ oscillations are readily observed in MSCs [24,74] and can affect stem cell differentiation $[58,59]$. In response to a fluid flow, Riddle et al. [75] have shown that shear stresses trigger flow rate-dependent increases in $\left[\mathrm{Ca}^{2+}\right]_{i}$ via the $\mathrm{IP}_{3}$ pathway in MSCs. Moreover, the substrate rigidity now appears to alter $\left[\mathrm{Ca}^{2+}\right]_{i}$ oscillations via RhoA/ROCK activity [73], suggesting that the substrate rigidity-dependent MSC differentiation [34] may be mediated by altered $\left[\mathrm{Ca}^{2+}\right]_{i}$ oscillations. Our laboratory has recently demonstrated that $\left[\mathrm{Ca}^{2+}\right]_{i}$ oscillations in MSCs are dramatically altered in response to the soluble factors and an electrical stimulation. Indeed, the physicochemical cues alter the calcium dynamics in MSCs to resemble that found in terminally differentiated osteoblasts [24]. Interestingly, a combination of osteogenic soluble factors with an electrical stimulation induced a synergistic differentiation of MSCs into osteoblasts at rates that are significantly faster than those induced by the soluble factors alone. However, application of an electrical stimulation by itself failed to induce MSC differentiation, suggesting that an externally applied physical cue may amplify but not necessarily activate the mechanisms involved in osteodifferentiation.

Multiple $\mathrm{Ca}^{2+}$ influx or efflux pathways are likely involved in the regulation of $\mathrm{Ca}^{2+}$ dynamics. At least 4 testable 


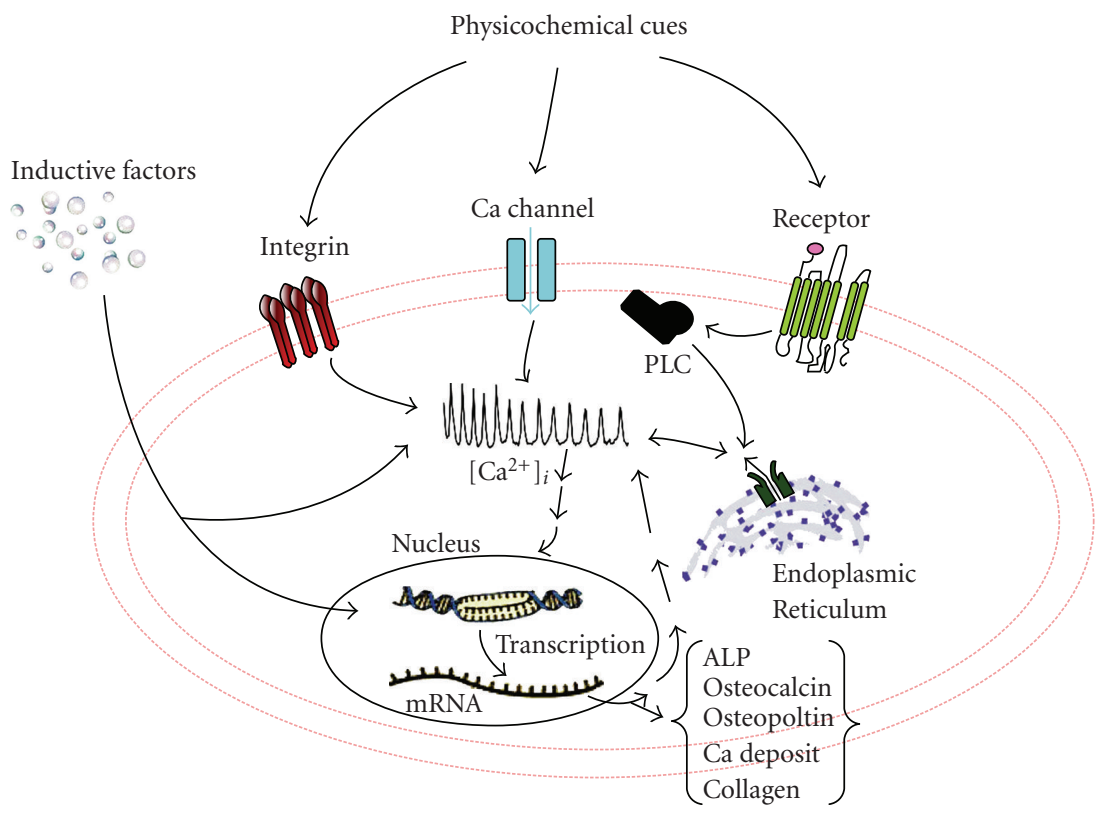

FIGURE 1: A schematic view of the potential effect of physicochemical cues for osteodifferentiation. The inductive factors can diffuse across the cell membrane and produce immediate effects, while physical cues can couple to the cell surface molecules. We envision that the mechanical or electrical cues can modulate the $\mathrm{Ca}^{2+}$ dynamics by coupling to (1) ion channels, (2) G-protein coupled receptor-activated molecules (e.g., PLC), (3) integrin-mediated focal adhesion, and (4) ATP release [21, 64].

ways are plausible in which the $\mathrm{Ca}^{2+}$ dynamics in MSCs are modulated (Figure 1). First, because the $\mathrm{Ca}^{2+}$ channels are known to sustain $\left[\mathrm{Ca}^{2+}\right]_{i}$ oscillation, MSCs should express these channels. Indeed, an abundance of the L-type channels fluorescently visualized in undifferentiated MSCs (data not shown) indicates that these channels are involved in the regulation of the $\left[\mathrm{Ca}^{2+}\right]_{i}$ oscillation. Treatment of cells with verapamil (a L-type inhibitor) or depletion of extracellular $\mathrm{Ca}^{2+}$ decreased the $\left[\mathrm{Ca}^{2+}\right]_{i}$ oscillation to the level comparable to that found in terminally differentiated osteoblasts [24]. These findings led to formulation of a postulate that extracellular $\mathrm{Ca}^{2+}$ is required to sustain the $\left[\mathrm{Ca}^{2+}\right]_{i}$ oscillation via the L-type $\mathrm{Ca}^{2+}$ channels. As MSCs undergo osteodifferentiation, the $\left[\mathrm{Ca}^{2+}\right]_{i}$ oscillation is decreased. Therefore, the role of L-type $\mathrm{Ca}^{2+}$ channels would be expected to diminish, suggesting that these channels may be down regulated. Second, we have shown that, when the PLC activity is inhibited, the $\left[\mathrm{Ca}^{2+}\right]_{i}$ oscillation is essentially abolished. This leads to another hypothesis that, as MSCs undergo osteodifferentiation, the PLC activity is reduced. Concomitant reduction of L-type channels and PLC activity may be coordinated to suppress the $\left[\mathrm{Ca}^{2+}\right]_{i}$ oscillation in MSCs undergoing osteodifferentiation. Third, integrins have been shown to regulate the $\mathrm{Ca}^{2+}$ dynamics which, in turn, control integrin-mediated adhesion [76], and cell migration through phosphorylation of focal adhesion kinase (FAK) [77]. This suggests a close association or correlation between differential focal adhesions formed in response to physicochemical cues and cell type-dependent $\left[\mathrm{Ca}^{2+}\right]_{i}$ oscillation. Fourth, MSCs were found to secrete ATP [68], and that autocrine and paracrine interactions involving purinergic receptors modulate $\left[\mathrm{Ca}^{2+}\right]_{i}$ oscillations.
Interestingly, we recently detected and characterized ATP release in response to an electrical stimulation [63]. Taken together, the physical cues may alter $\mathrm{Ca}^{2+}$ dynamics mediated in part by ATP secretion.

Whether MSCs are capable of differentiation toward the neural lineage remains still controversial [78]. While several laboratories have shown evidence for induction of neuron-like cell, astrocytes, and glial cells [16, 79-82], other reports suggest that in vitro differentiation protocols for bone marrow stromal cells disrupt actins and apparent neuronal morphology is therefore observed [83], or cellular makers in response to the neuroinductive factors could be attributed to cellular toxicity and changes in the cytoskeleton [84]. Although the opposing findings should carefully be considered, the biochemical [85] or substrate stiffness [34] induction of neuron-like cells from human MSCs does exhibit rapid $\left[\mathrm{Ca}^{2+}\right]_{i}$ oscillation. In fact, the $\mathrm{Ca}^{2+}$ dynamics profiles found in these cells differ in many ways. For example, the initial response to the neuroinductive factors suppressed the $\left[\mathrm{Ca}^{2+}\right]_{i}$ oscillation, similar to that found during osteodifferentiation. However, MSCs undergoing neurogenesis quickly regain the capability to sustain the $\left[\mathrm{Ca}^{2+}\right]_{i}$ oscillation in less than 7 days. In addition, the $\left[\mathrm{Ca}^{2+}\right]_{i}$ oscillation profiles are also distinctively different (Figure 2). Those cells undergoing neurodifferentiation exhibit a pattern that consists of numerous $\mathrm{Ca}^{2+}$ spikes of both small and large amplitude. This type of pattern is unique to the neurogenic cells and not found in any of the five cell types we have tested thus far, including undifferentiated human or rat MSCs, P19 mouse embryonic stem cells, osteoblasts, fibroblasts, and even primary myocytes. Unlike non-excitable cells however, the $\mathrm{N}$-type $\mathrm{Ca}^{2+}$ channels are expected to play 
a major role in neuronal cells. We detect essentially no Ntype channels expressed in the undifferentiated stem cells, suggesting that the $\mathrm{N}$-type channels are rapidly up-regulated [86]. In addition, the N-type channels are modulated by the extracellular signal-regulated kinase (ERK)-dependent phosphorylation [87]. Since ERK activation is also involved in stem cell differentiation, up-regulation of the $\mathrm{N}$-type $\mathrm{Ca}^{2+}$ channels is expected as MSCs undergo neurodifferentiation. Similarly, the PLC activity should be increased in response to the neuroinductive factors. These findings provide evidence that the altered $\mathrm{Ca}^{2+}$ dynamics may be unique to the tissue type and perhaps be used as an early indicator to predict MSC differentiation into the neurogenic phenotype.

\subsection{Mitogen-Activated Protein Kinase Signaling Pathways.}

The mitogen-activated protein (MAP) kinases are the serine/threonine kinases that respond to extracellular signals. They are also known to mediate signal transduction from the cell surface to nucleus [88]. In addition to several important physiological responses, the role of MAP kinases in proliferation and differentiation has been well documented and established [89]. Unregulated MAP kinase signaling, for example, has been implicated in many types of tumors [90-92]. It also appears that, at least for osteogenic differentiation, sustained MAP kinase activation promotes cell differentiation [93], suggesting an interesting hypothesis that a physical stimulation may be used to sustain and prolong the MAP kinase activation. At least three major modules of the MAP kinase signaling cascades have been identified, including the extracellular signal-regulated kinase (ERK), the c-Jun amino-terminal kinase/stress activated protein kinase (JNK/SAPK), and the p38 kinase [94]. Of these three modules, the ERK signaling pathway represents the most extensively studied mechanism. Although all three MAP kinase modules are involved in various biological processes, the ERK pathway is associated particularly with cell proliferation and differentiation [95-97]. The JNK/SAPK kinases have been shown to respond to external stress including heat shock, and cytokines. Interestingly, when cells are treated with mitogenic agents, the ERKs but not JNK/SAPKs are the dominant signaling pathways. In contrast, cells exposed to a stress typically utilize the JNK/SAPK pathway without significantly altering the ERK activities [98, 99]. This observation raises a rather important hypothesis that, when cells are exposed to external physical stimuli in the presence of the mitogenic agents, the differential activation of MAP kinases could be combined, and synergistic biological responses such as cell proliferation and differentiation may be induced. It is noted here however that, in response to mechanical stimulation, the ERK and p38 kinase cascades can be activated $[100,101]$, and tethering and rolling of neutrophils in shear flow activates integrins and induces firm adhesion through phosphorylation of the p38 kinase [102].

Unlike soluble factors that can readily bind to their receptors with a degree of specificity, the physical cues do not preferentially discriminate the targets. However, evidence has been gathered to suggest that there are potential candidates that may transduce the external physical stimuli. For example, several mechanotranducers have been identified

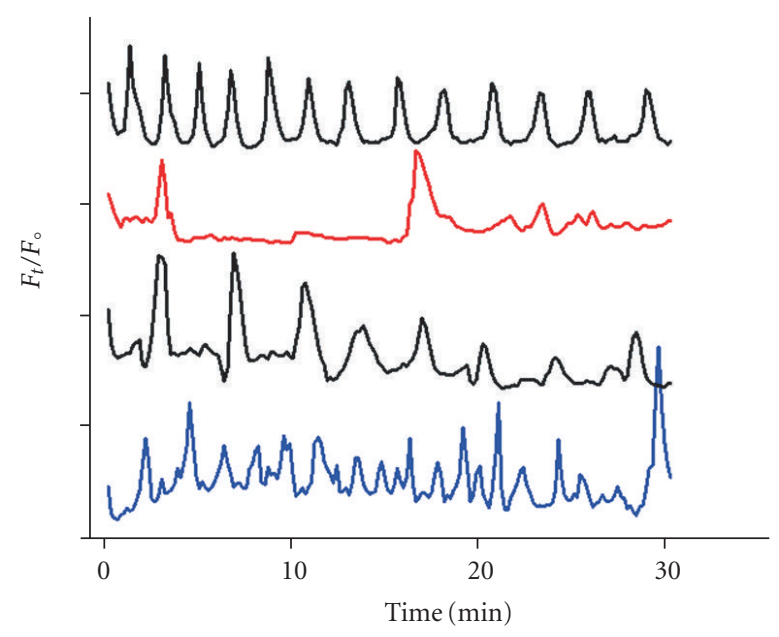

(a)

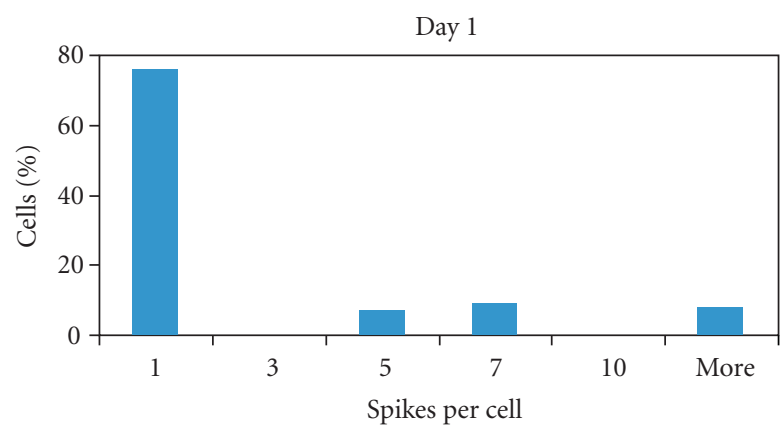

(b)

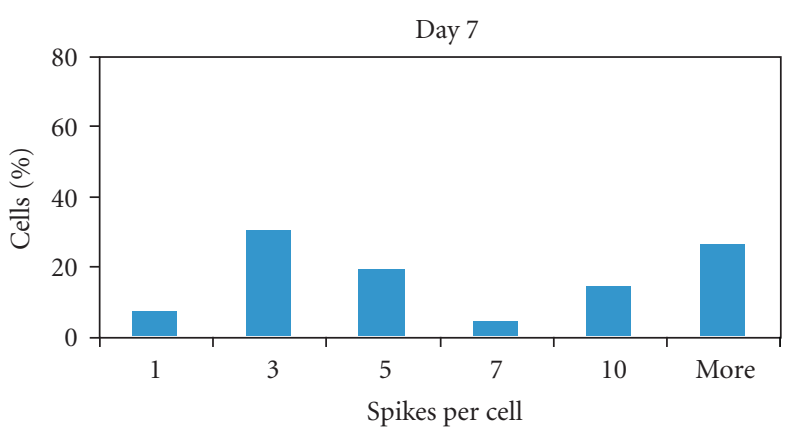

(c)

Figure 2: Typical temporal profiles of $\left[\mathrm{Ca}^{2+}\right]_{i}$ oscillation observed in human MSC neurodifferentiation. The cell-type dependent characteristics of the $\left[\mathrm{Ca}^{2+}\right]_{i}$ oscillations are displayed (a). The undifferentiated human MSCs show a pattern of regular $\left[\mathrm{Ca}^{2+}\right]_{i}$ oscillation (top trace). The $\left[\mathrm{Ca}^{2+}\right]_{i}$ oscillations become suppressed and irregular in time for human MSCs undergoing osteodifferentiation (second trace; at week 3). For comparison, we monitored the $\left[\mathrm{Ca}^{2+}\right]_{i}$ oscillation in primary myocytes (third trace). The human MSCs undergoing neurodifferentiation, however, show yet another pattern of the $\left[\mathrm{Ca}^{2+}\right]_{i}$ oscillation (bottom trace; at day 5) that resemble neither the undifferentiated human MSCs nor other cell types. Further, the $\left[\mathrm{Ca}^{2+}\right]_{i}$ oscillation profiles of myocytes and neuronal cells could be distinguished. Unlike the undifferentiated human MSCs, the neurogenic cells exhibit multiple $\left[\mathrm{Ca}^{2+}\right]_{i}$ oscillations and spikes whose amplitudes vary substantially. The two panels (b) and (c) show the distribution of the $\mathrm{Ca}^{2+}$ spikes measured at the day 1 and 7 of MSC neurodifferentiation, respectively. 


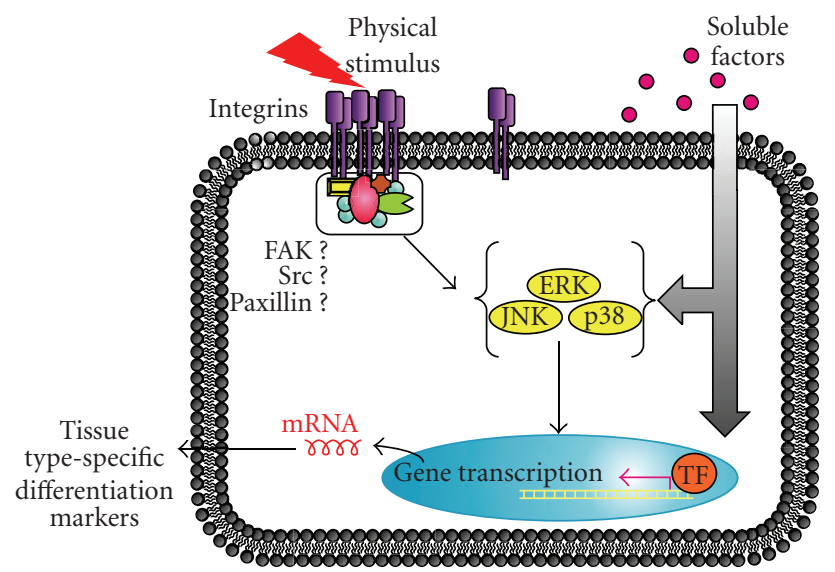

(a)

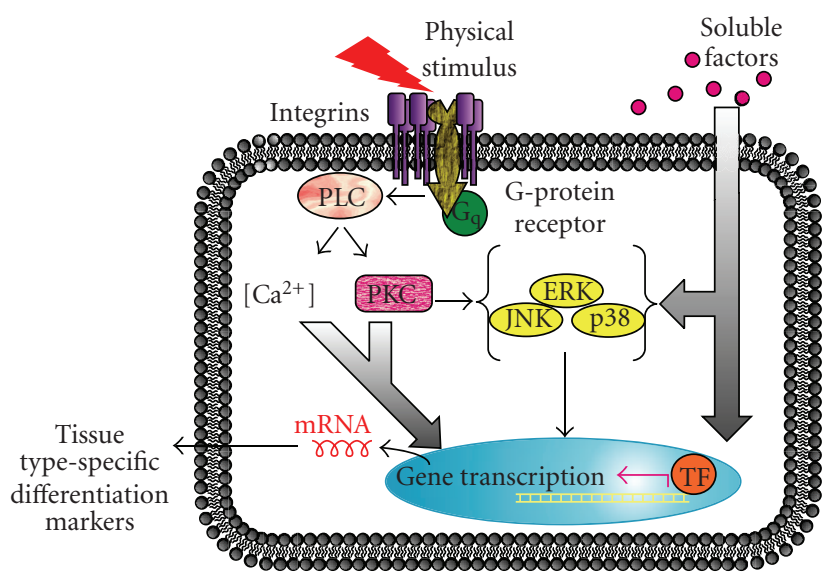

(b)

FIgURE 3: Two alternate coupling molecular mechanisms. The soluble factors are known to play an important role in stem cells differentiation (thicker arrows). (a) A physical stimulus may affect cell differentiation synergistically in the presence of the soluble factors via integrins and the MAP kinase signaling system. The physical stimulus causes integrin redistribution, clustering, activation, and assembly of some focal adhesion proteins such as FAK, paxillin, vinculin, src, and others. Enzymatic activity of assembled proteins (e.g., FAK or src) causes further MAP kinase activation. In effect, the MAP kinase cascade is amplified and cell differentiation may be accelerated. (b) Alternative mechanism involves activation of other receptors (e.g., G-proteins receptors) in the cell membrane. This leads to the PLC enzyme-mediated signaling through $\mathrm{Ca}^{2+}$ and protein kinase $\mathrm{C}$ (PKC) in multiple pathways. Not all intricate signaling effects of these secondary messengers are shown. However, PKC activation can be effectively coupled to the MAP kinase cascades.

that include integrin-dependent focal adhesion [103-107] and ion channels [108, 109], and integrin clustering has been shown to be responsible for transducing electrical stimulation $[110,111]$. In addition to the critical role in formation of focal adhesions, integrins are also linked to cell proliferation, differentiation, migration, and apoptosis $[112,113]$. Moreover, integrins are essential for normal development of hematopoietic lineages and bone marrow by regulating cell proliferation and differentiation [114], and cardiomyocyte cell cycle depends on cell attachment via $\beta_{1}$ integrins [115]. Integrin expression level is often associated with cell differentiation. For example, neuronal differentiation involves down-regulation of integrins [116]. At successive stage of the osteoblast lineages, cells show differential patterns of integrin expression [117]. In spite of these diverse cellular responses regulated by integrins, the interactions between stromal precursor cells and extracellular matrix are not clearly understood. It appears clear that the integrinmatrix interaction can activate MAP kinases, thus suggesting that MAP kinases act as one of the key molecules that connect integrins at the cell surface with adhesion-dependent gene expressions [88]. Interestingly, some findings suggest that integrin can regulate activation of growth factor receptors by co-clustering and thereby stimulate MAP kinase signaling [118]. Another likely candidate is via G-proteins. Indeed, activation of phospholipase C (PLC) is a key event that modulates altered calcium dynamics and subsequent production of yet another secondary messenger, diacylglycerol (DAG). DAG can lead to activation of protein kinase C (PKC) that, in turn, activates MAP kinase cascades for proliferation and differentiation [119]. This G-protein mechanism has been demonstrated in human osteoblasts [51] and human MSCs [24] using specific PLC inhibitors (e.g., U73122) and also by blocking PKC (e.g., bisindolylmaleimideI). Two coupling mechanisms are therefore envisioned to activate the MAP kinase cascades. Soluble factors (e.g., dexamethasone) typically regulate cell differentiation through multiple biochemical mechanisms (Figure 3, thick arrows) including MAP kinase signal transduction. The commitment of MAP kinases results in activation of various transcription factors (e.g., AP-1, Cbfa1/Runx2) and, in the case of osteodifferentiation, up-regulation of osteoblast-specific genes [120]. The first coupling mechanism (Figure 3(a)) affects cell differentiation via integrins and the MAP kinase signaling pathways. This physical stimulus causes integrin redistribution, clustering, activation, and assembly of some focal adhesion proteins such as focal adhesion kinase (FAK), paxillin, vinculin, src $[121,122]$. Enzymatic activity of assembled proteins (e.g., FAK or src) causes further MAP kinase activation [123]. Such assembly of adhesion proteins may mimic the integrin-matrix interactions, which are known to regulate the MAP kinase activities. In effect, the MAP kinase cascade is synergistically amplified and cell differentiation is facilitated. Alternatively, the second coupling mechanism involves activation of G-protein coupled receptors in the cell membrane (Figure 3(b)) that leads to the PKC pathway. $\mathrm{PKC}$ activation is then effectively coupled to the MAP kinase cascades and thus promoting osteodifferentiation.

3.3. Biomechanical Remodeling. A cell has a remarkable capability to detect external physical forces of various modalities and adapt to the biomechanical environment by adjusting its mechanical properties to match those of the surrounding tissue. Clearly, cells do respond to the physical forces and mechanically remodel themselves in order to transduce the physical signals. The concept of mechanotransduction 
relies on the bi-directional cross-talk between the cell and microenvironment $[108,124,125]$ that modulates biochemistry in the cytoplasm and ultimately affects the nucleus [126]. Cytoskeleton is thought to be one of the most significant cellular mechanical components and provides structural stability and elasticity to the cell undergoing multiple deformations without losing its integrity [127, 128]. In addition, the cytoskeleton has now been shown to mediate complex intracellular signaling pathways [108]. Therefore, the cytoskeleton is referred to as a mechanotransducer that regulates the cytoskeleton-associated signaling cascades, such as Rho family GTPases (e.g., RhoA, Cdc42, Rac) [129]. In this way, the cytoskeleton mediates cell response to changing biomechanical environment (e.g., substrate stiffness, cell shape and deformation, external pressure, shear stress) by structural rearrangement of the cytoskeleton itself, or alterations in gene expression profiles, cell adhesion, and secretion of extracellular matrix (i.e., bi-directional reciprocity) $[127,130]$. Complex interactions between these multiple signaling molecules, likely triggered by external signals, cause activation of downstream target proteins, which could lead to a global structural rearrangement of the cytoskeleton or altered gene transcription profiles affecting cell adhesion, secretion of extracellular matrix components, and cell metabolic activity. Substantial structural and functional differences of cytoskeletons in cells of the same mesodermal origin (myocytes, osteoblasts, endothelial cells, kidney cells, etc.) imply that the cytoskeleton may also participate in cell differentiation.

The plasma membrane is also known to play an important role in determining the cellular biomechanics. Due to the important role of the membrane in many cellular functions, it is likely involved in the intricate interplay of events accompanying cell differentiation. Beside its function as a barrier from the outer environment, it participates in inward-outward trafficking, motility, cell adhesion to extracellular matrix, and cell-cell interaction [131, 132]. These and many other intracellular events are regulated by the membrane surface tension, which is maintained by several mechanisms including membrane reservoir and lipid material turnover $[132,133]$. Generally, the membrane tension is determined by the lipid bilayer composition (e.g., cholesterol content) [134], and the membrane interaction with the cytoskeleton via specific biomolecular links such as linker proteins [135]. We have recently shown that the plasma membrane attachment to the cytoskeleton in fully differentiated osteoblasts is much stronger than in undifferentiated human MSCs [136]. Functionally, a strong membrane-cytoskeleton adhesion should be beneficial to keep the structural integrity of osteoblasts subjected to continuous stress cycles. In human MSCs, a lower membrane tension is observed that may better facilitate endo- and exocytosis and contributes to a higher sensitivity of these unqiue cells to various soluble biochemical environmental stimuli. Moreover, we have recently reported an interesting observation $[21,63]$ that the cell type-dependent linkage between the membrane-cytoskeleton could be regulated by the linkers proteins [137-141], including ezrin, radixin, and moesin (ERM proteins). For example, the ERM proteins' expression and distribution are clearly different in human MSCs and osteoblasts [21]. Interestingly, because the ERM proteins are substrate for RhoA [142], the involvement of RhoA in stem cell differentiation in response to the extracellular environment [33] may now be better understood and is likely to depend on the ERM protein distribution and activation.

Mechanotranduction may be mediated by the target molecules at the cell surface or by a "hire-wired" tensegrity network of cytoskeleton [108, 126, 143]. In response to a physical force, mechanically sensitive molecules such as integrins, ion channels, and G-protein coupled receptors could be activated and initiate downstream signaling cascades and alter gene expression $[108,109,144]$. This view of mechanotranduction has been supported by evidence that includes integrin blocking by antibodies [111, 145] and inhibiting stretch-activated cation channels (SACCs) [146, 147]. Alternatively, the tensegrity model postulates a rapid and coordinated response to a physical force by rearranging the cytoskeletal and nuclear elements $[126,143]$. This model has gained much attention due to the fact that it provides an architectural description of mechanotransduction and that it can support a long range force transmission to influence the nucleus directly [126]. Based on our recent findings, we propose yet another alternative model that integrates the membrane-cytokseleton coupling into the overall cellular biomechanics. Incorporating AFM-based microindentation technique to measure the cellular elasticity and assessing the membrane tension by optically pulling membrane tethers from the cell body $[63,136]$, the terminally differentiated cells (e.g., osteoblasts) show a lower elastic modulus and formation of shorter membrane tethers. These are in direct contrast to MSCs in which the elastic modulus is much higher and the membrane tethers are significantly longer. Since the elasticity is primarily determined by actins, the actin stress fibers are found likely in large bundles in stem cells. Moreover, the membrane-cytoskeletal association can be probed by optically pulling the membrane tethers. Significantly longer tether lengths observed in stem cells are indicative of a weak association between the two components that determine the overall cellular biomechanics.

As illustrated in Figure 4, the plasma membrane is strongly associated with the underling meshwork of thin actin fibers through multiple linker proteins and focal adhesions in osteoblasts. In contrast stem cells, especially in MSCs, express thick actin stress fibers that are connected to the membrane only at few discreet sites (e.g., focal adhesions). As a result, the overall membrane-cytoskeleton adhesion in MSCs is weaker and the optically extracted membrane tethers are therefore longer. However, thick bundled actin structure in MSCs provides a higher elastic modulus. Remodeling of the actin cytoskeleton is also expected to regulate the membrane receptor dynamics [148]. Moreover, actin remodeling and physical coupling between the cell membrane and cytoskeleton, mediated by linker proteins, are now shown to be responsible for such dramatically different biomechanical properties [21]. Indeed, recent work from our laboratory indicates that, when human MSCs are transfected to transiently suppress the ERM 


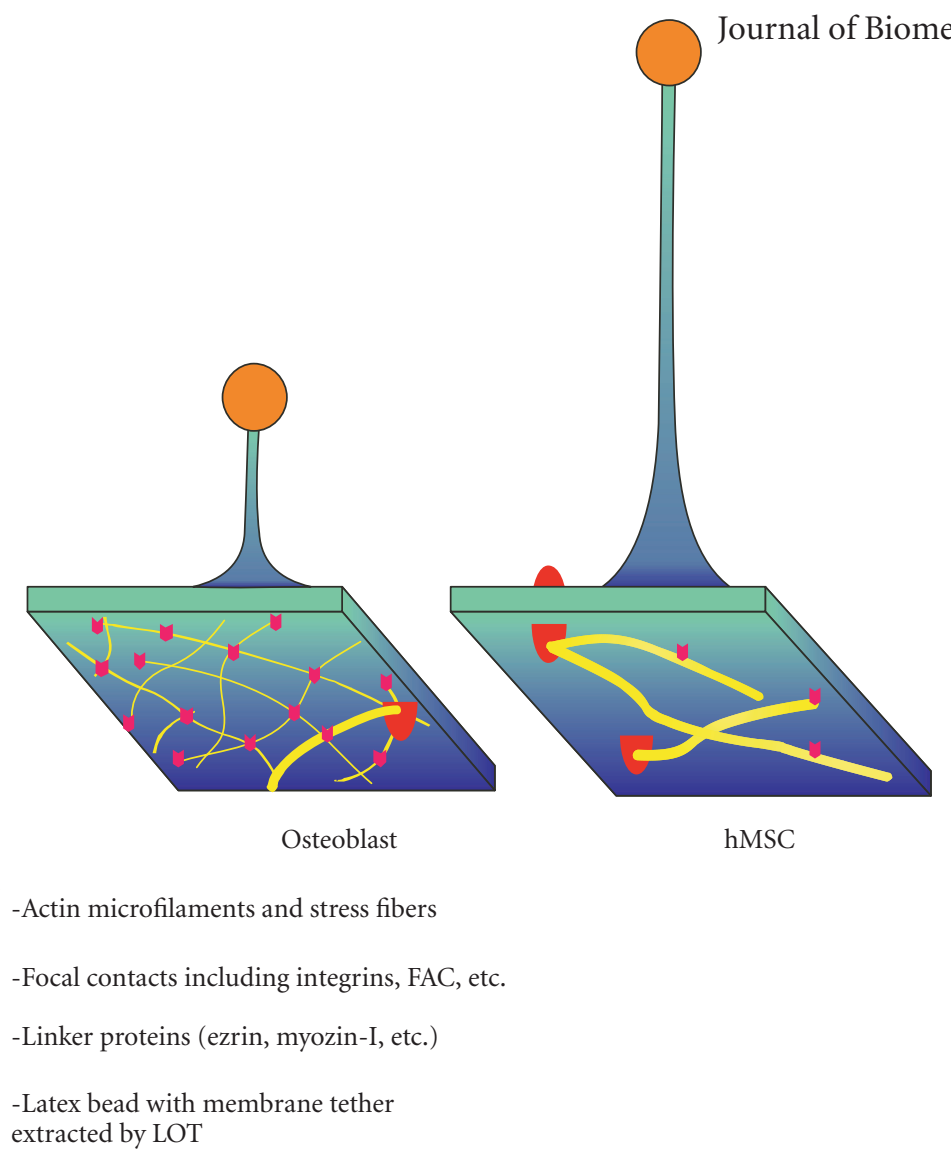

FIGURE 4: Model for differential cellular mechanics in human MSCs and osteoblasts. Thin and dense actin filaments in osteoblasts are tightly bound to the plasma membrane through multiple linker proteins (e.g, ATP-dependent ERM proteins) and focal complexes. Thicker stress fibers in human MSC are associated with the membrane mostly at the focal contacts due to a smaller contact area with the membrane and thus lower availability of protein linker binding sites. As result, in human MSC the overall membrane-cytoskeleton adhesion is weaker, and longer membrane tethers are formed that reflects a lower membrane tension. However, thick bundled actin structure in human MSCs provides a higher elastic modulus.

linker proteins (ezrin, radixin, and moesin), osteogenic differentiation is either delayed or perhaps inhibited, and the cell membrane-cytoskeleton coupling is weakened. For example, the transfected human MSCs maintained similar biomechanical properties that are characteristics of undifferentiated stem cells, even though the osteogenic factors are present. An additional observation indicates a decrease in the intracellular ATP level and possibly ATP release in response to an external physical stimulation, providing more evidence that the ATP-dependent ERM proteins may be a key player [21]. The ERM proteins function not only as the connector linking the membrane with microfilaments but also are now known to regulate signaling. Of particular interest are their interaction with Rho-A. The role of RhoA in mechanically guided MSC differentiation has been shown $[33,34]$. The ERM protein expression is cell typedependent and also appears to have been redistributed when stem cells undergo differentiation [21]. Moreover, the cellular biomechanical measurements indicate that the membrane-cytoskeleton coupling, as assessed by tether lengths, strengthens significantly during osteodifferentiation. This is consistent with the ERM proteins' expression that promotes a stronger association between the cell membrane and cytoskeleton.
3.4. Integrative Physicochemical Model. An integrative physicochemical model emerges for the regulation of stem cells. While this model is not intended to represent an exhaustive list of possibly numerous pathways, the differentiation cues may influence the cellular biomechanics through utilizing both $\mathrm{Ca}^{2+}$-dependent and -independent pathways (see Figure 5). Soluble factors either bind to the cell surface receptors or diffuse through the cell membrane, and alter gene expressions, modulate $\left[\mathrm{Ca}^{2+}\right]_{i}$ oscillation and reorganize cytoskeleton [21]. An external physical stimulus induces an increase in the $\left[\mathrm{Ca}^{2+}\right]_{i}$ mediated either by $\mathrm{Ca}^{2+}$ influx across the cell membrane or $\mathrm{Ca}^{2+}$ release from intracellular storage. An elevated $\left[\mathrm{Ca}^{2+}\right]_{i}$ level is likely to cause depolymerization of F-actins and therefore an overall decrease in the cell elasticity, thus reinforcing the effects of the soluble factors. Recent studies suggest that, similar to a physical stimulus, the substrate matrix stiffness also can reorganize the actin cytoskeleton via the RhoA/ROCK pathway [34] and alter the $\left[\mathrm{Ca}^{2+}\right]_{i}$ oscillation [73]. Independent of an increase in the $\left[\mathrm{Ca}^{2+}\right]_{i}$, the physical stimulus causes a depletion in the intracellular ATP (e.g., ATP release), which in turn leads to inhibition of ERM proteins' binding affinity and dissociation of the cytoskeleton from the membrane. The resulting membrane separation from 


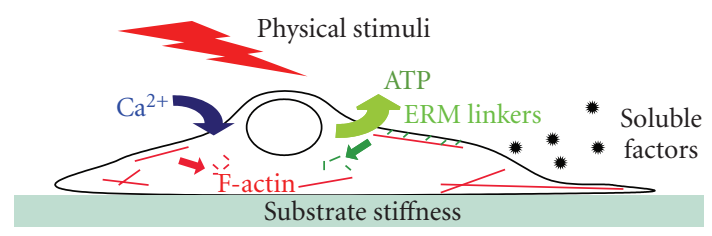

FIGURE 5: Schematic for an integrative model that depicts coupling mechanisms mediating the effects of physicochemical cues. In addition to effects induced by the soluble factors, an external physical stimulus induces an increase in the cytosolic calcium concentration, which depolymerizes the F-actins and decrease the cell elasticity. The physical stimuli can also cause depletion of intracellular ATP, for example, by ATP release that, in turn, leads to inhibition of the ERM protein linkers' binding properties and their dissociation from the membrane and actin cytoskeleton. A separation of the cell membrane from the cytoskeleton occurs and effectively decreases the membrane tension, attributable both to down-regulation of active ERM proteins and actin depolymerization. Altered calcium dynamics along with cytoskeletal remodeling may not simply be consequences of stem cell differentiation but rather important key factors regulating it.

the cytoskeleton and a decrease in the membrane tension are attributed both to induced down-regulation of active ERM linker proteins and actin depolymerization. The linker proteins seem to play a significant role in modulation of the cell mechanics that is a critical factor in the regulation and even manipulation of stem cells.

It is interesting to know that an electrical stimulation alone fails to initiate MSC osteodifferentiation but, when combined with the soluble factors, causes a synergistic stem cell differentiation [24]. In the context of the proposed model, an explanation can be provided that, as thick stress fibers appear less stable than thin microfilaments, the stress fibers are disassembled initially under an electrical exposure. This brings the cell elastic and structural properties closer to those of fully differentiated osteoblasts, and induces the cell membrane dissociation from cytoskeleton, and consequently decreases the membrane tension to enhance endocytosis and transmembrane trafficking of the soluble factors. When cells are allowed to recover following the electrical exposure in presence of soluble factors, a further rearrangement of actin and ERM proteins will proceed along with expression of osteogenic markers. In contrast, neuronal cells exhibit a very weak actin cytoskeleton and a relatively loose plasma membrane as indicated by the tether extraction experiments [149]. Therefore, a higher physical stimulation might be required to facilitate neurogenic differentiation, which will maximally disrupt the actin cytoskeleton and inhibit ERM linkers, suggesting a plausible approach for precisely controlling the physical parameters for selective manipulation of mechanical properties of a particular and pre-selected cell phenotype. Taken together, optimal use of the physicochemical cues may lead the researcher to develop strategies for tissue engineering by manipulating cell differentiation, mobility, and cell incorporation into engineered scaffolds, and eventual maturation of tissue substitutes. An in depth understanding of mechanisms that allow regulation of the cell biomechanical and biochemical properties will undoubtedly lead to a more effective development of therapeutics for regenerative medicine.

\section{Conclusions}

It is clear that stem cells respond to various physicochemical factors. While biologists have long appreciated the important role for soluble factors in the regulation of stem cell differentiation, the mechanical and electrical stimuli are now firmly established to significantly influence the stem cell fate. Therefore, the idea of combining multiple differentiation cues is gaining traction and could lead to an active research area of stem cells and perhaps unravel their intricate biological and physical properties. Future work should include execution and full analysis of multifactorial design experiments in which the presumed orthogonal cues (e.g., soluble biochemical and physical force are noninteractive) might interact to produce higher order effects [150]. One example might be to vary the concentration of soluble factors that many laboratories currently use. Induction protocols using a lesser amount of soluble factors could be just as potent when combined with suitable physical cues. However, completion of the all possible combinatory experiments may be laborious, and it is unlikely that we can determine a set of combinational cues that is widely applicable irrespective of tissue phenotypes. Rather, for an intended tissue phenotype, the physicochemical cues would have to be optimized for this particular phenotype that is distinctively different from others morphologically and functionally (e.g., excitable versus non-excitable tissues). In spite of such difficulties, advances in the molecular, biophysical, and imaging tools should allow a more detailed understanding of the coupling mechanisms that regulate stem cell differentiation in the near future. Establishment of new paradigms in which stem cells can be manipulated physicochemically will undoubtedly expedite the current effort for stem cell-based regenerative medicine by targeting specific combinations of physicochemical cues that optimally exploit the unique biological and biophysical properties of stem cells for the intended differentiation.

\section{Acknowledgments}

This work was supported, in part, by National Institutes of Health grants (GM060741, EB006067) and by a grant from the Office of Navy Research (N00014-06-1-0100), and by a National Research Foundation of Korea (NRF) Grant funded by the Korean government (MEST) (no. 2007-0056690, JHS).

\section{References}

[1] O. Naveiras and G. Q. Daley, "Stem cells and their niche: a matter of fate," Cellular and Molecular Life Sciences, vol. 63, no. 7-8, pp. 760-766, 2006.

[2] A. Wilson and A. Trumpp, "Bone-marrow haematopoieticstem-cell niches," Nature Reviews Immunology, vol. 6, no. 2, pp. 93-106, 2006. 
[3] R. Galli, A. Gritti, L. Bonfanti, and A. L. Vescovi, "Neural stem cells: an overview," Circulation Research, vol. 92, no. 6, pp. 598-608, 2003.

[4] A. M. Christiano, "Epithelial stem cells: stepping out of their niche," Cell, vol. 118, no. 5, pp. 530-532, 2004.

[5] V. Tropepe, B. L. K. Coles, B. J. Chiasson, et al., "Retinal stem cells in the adult mammalian eye," Science, vol. 287, no. 5460, pp. 2032-2036, 2000.

[6] V. K. Ramiya, M. Maraist, K. E. Arfors, D. A. Schatz, A. B. Peck, and J. G. Cornelius, "Reversal of insulin-dependent diabetes using islets generated in vitro from pancreatic stem cells," Nature Medicine, vol. 6, no. 3, pp. 278-282, 2000.

[7] X. C. He, J. Zhang, W. G. Tong, et al., "BMP signaling inhibits intestinal stem cell self-renewal through suppression of Wnt$\beta$-catenin signaling," Nature Genetics, vol. 36, no. 10, pp. 1117-1121, 2004.

[8] K. A. Moore and I. R. Lemischka, "Stem cells and their niches," Science, vol. 311, no. 5769, pp. 1880-1885, 2006.

[9] P. Seale, A. Asakura, and M. A. Rudnicki, "The potential of muscle stem cells," Developmental Cell, vol. 1, no. 3, pp. 333342, 2001.

[10] S. L. McKinney-Freeman, K. A. Jackson, F. D. Camargo, G. Ferrari, F. Mavilio, and M. A. Goodell, "Muscle-derived hematopoietic stem cells are hematopoietic in origin," Proceedings of the National Academy of Sciences of the United States of America, vol. 99, no. 3, pp. 1341-1346, 2002.

[11] K. Le Blanc, C. Tammik, K. Rosendahl, E. Zetterberg, and O. Ringden, "HLA expression and immunologic properties of differentiated and undifferentiated mesenchymal stem cells," Experimental Hematology, vol. 31, no. 10, pp. 890-896, 2003.

[12] J. Ryan, F. Barry, J. M. Murphy, and B. P. Mahon, "Human mesenchymal stem cells evade allogeneic immune responses," Immunology, vol. 116, p. 102, 2005.

[13] M. F. Pittenger, A. M. Mackay, S. C. Beck, et al., "Multilineage potential of adult human mesenchymal stem cells," Science, vol. 284, no. 5411, pp. 143-147, 1999.

[14] J. Sanchez-Ramos, S. Song, F. Cardozo-Pelaez, et al., "Adult bone marrow stromal cells differentiate into neural cells in vitro," Experimental Neurology, vol. 164, no. 2, pp. 247-256, 2000.

[15] A. Hermann, S. Liebau, R. Gastl, et al., "Comparative analysis of neuroectodermal differentiation capacity of human bone marrow stromal cells using various conversion protocols," Journal of Neuroscience Research, vol. 83, no. 8, pp. 15021514, 2006.

[16] F. Scintu, C. Reali, R. Pillai, et al., "Differentiation of human bone marrow stem cells into cells with a neural phenotype: diverse effects of two specific treatments," BMC Neuroscience, vol. 7, article 14, 2006.

[17] P. A. Zuk, M. Zhu, H. Mizuno, et al., "Multilineage cells from human adipose tissue: implications for cell-based therapies," Tissue Engineering, vol. 7, no. 2, pp. 211-228, 2001.

[18] P. Bosch, D. S. Musgrave, J. Y. Lee, et al., "Osteoprogenitor cells within skeletal muscle," Journal of Orthopaedic Research, vol. 18, no. 6, pp. 933-944, 2000.

[19] C. De Bari, F. Dell'Accio, P. Tylzanowski, and F. P. Luyten, "Multipotent mesenchymal stem cells from adult human synovial membrane," Arthritis and Rheumatism, vol. 44, no. 8, pp. 1928-1942, 2001.

[20] A.-M. Rodriguez, C. Elabd, F. Delteil, et al., "Adipocyte differentiation of multipotent cells established from human adipose tissue," Biochemical and Biophysical Research Communications, vol. 315, no. 2, pp. 255-263, 2004.
[21] I. Titushkin and M. Cho, "Regulation of cell cytoskeleton and membrane mechanics by electric field: role of linker proteins," Biophysical Journal, vol. 96, no. 2, pp. 717-728, 2009.

[22] A. Alhadlaq, J. H. Elisseeff, L. Hong, et al., "Adult stem cell driven genesis of human-shaped articular condyle," Annals of Biomedical Engineering, vol. 32, no. 7, pp. 911-923, 2004.

[23] N. R. Jorgensen, Z. Henriksen, O. H. Sørensen, and R. Civitelli, "Dexamethasone, BMP-2, and 1,25dihydroxyvitamin D enhance a more differentiated osteoblast phenotype: validation of an in vitro model for human bone marrow-derived primary osteoblasts," Steroids, vol. 69, no. 4, pp. 219-226, 2004.

[24] S. Sun, Y. M. Liu, S. Lipsky, and M. R. Cho, "Physical manipulation of calcium oscillations facilitates osteodifferentiation of human mesenchymal stem cells," FASEB Journal, vol. 21, pp. 1472-1480, 2007.

[25] K. Tsuchiya, G. Chen, T. Ushida, T. Matsuno, and T. Tateishi, "The effect of coculture of chondrocytes with mesenchymal stem cells on their cartilaginous phenotype in vitro," Materials Science and Engineering C, vol. 24, no. 3, pp. 391-396, 2004.

[26] D. R. Martin, N. R. Cox, T. L. Hathcock, G. P. Niemeyer, and H. J. Baker, "Isolation and characterization of multipotential mesenchymal stem cells from feline bone marrow," Experimental Hematology, vol. 30, no. 8, pp. 879-886, 2002.

[27] M. Ryden, A. Dicker, C. Gootherstrom, et al., "Functional characterization of human mesenchymal stem cell-derived adipocytes," Biochemical and Biophysical Research Communications, vol. 311, no. 2, pp. 391-397, 2003.

[28] N. R. Blondheim, Y. S. Levy, T. Ben-Zur, et al., "Human mesenchymal stem cells express neural genes, suggesting a neural predisposition," Stem Cells and Development, vol. 15, no. 2, pp. 141-164, 2006.

[29] P. Tropel, N. Platet, J.-C. Platel, et al., "Functional neuronal differentiation of bone marrow-derived mesenchymal stem cells," Stem Cells, vol. 24, no. 12, pp. 2868-2876, 2006.

[30] S. Wenisch, K. Trinkaus, A. Hild, et al., "Immunochemical, ultrastructural and electrophysiological investigations of bone-derived stem cells in the course of neuronal differentiation," Bone, vol. 38, no. 6, pp. 911-921, 2006.

[31] G. Bartsch Jr., J. J. Yoo, P. De Coppi, et al., "Propagation, expansion, and multilineage differentiation of human somatic stem cells from dermal progenitors," Stem Cells and Development, vol. 14, no. 3, pp. 337-348, 2005.

[32] C. Y. Xu, R. Inai, M. Kotaki, and S. Ramakrishna, "Aligned biodegradable nanofibrous structure: a potential scaffold for blood vessel engineering," Biomaterials, vol. 25, pp. 877-886, 2004.

[33] R. McBeath, D. M. Pirone, C. M. Nelson, K. Bhadriraju, and C. S. Chen, "Cell shape, cytoskeletal tension, and RhoA regulate stem cell lineage commitment," Developmental Cell, vol. 6, pp. 483-495, 2004.

[34] A. J. Engler, S. Sen, H. L. Sweeney, and D. E. Discher, "Matrix elasticity directs stem cell lineage specification," Cell, vol. 126, no. 4, pp. 677-689, 2006.

[35] B. Geiger, A. Bershadsky, R. Pankov, and K. M. Yamada, "Transmembrane extracellular matrix-cytoskeleton crosstalk," Nature Reviews Molecular Cell Biology, vol. 2, no. 11, pp. 793-805, 2001.

[36] C. Krabbe, E. Courtois, P. Jensen, et al., "Enhanced dopaminergic differentiation of human neural stem cells by synergistic effect of Bcl-xL and reduced oxygen tension," Journal of Neurochemistry, vol. 110, no. 6, pp. 1908-1920, 2009. 
[37] G. H. Altman, R. L. Horan, I. Martin, et al., "Cell differentiation by mechanical stress," The FASEB Journal, vol. 16, no. 2, pp. 270-272, 2002.

[38] T. Yoshikawa, S. A. F. Peel, J. R. Gladstone, and J. E. Davies, "Biochemical analysis of the response in rat bone marrow cell cultures to mechanical stimulation," Bio-Medical Materials and Engineering, vol. 7, no. 6, pp. 369-377, 1997.

[39] G. H. Altman, H. H. Lu, R. L. Horan, et al., "Advanced bioreactor with controlled application of multi-dimensional strain for tissue engineering," Journal of Biomechanical Engineering, vol. 124, no. 6, pp. 742-749, 2002.

[40] C. A. Simmons, S. Matlis, A. J. Thornton, S. Chen, C.-Y. Wang, and D. J. Mooney, "Cyclic strain enhances matrix mineralization by adult human mesenchymal stem cells via the extracellular signal-regulated kinase (ERK1/2) signaling pathway," Journal of Biomechanics, vol. 36, no. 8, pp. 10871096, 2003.

[41] R. D. Sumanasinghe, S. H. Bernacki, and E. G. Loboa, "Osteogenic differentiation of human mesenchymal stem cells in collagen matrices: effect of uniaxial cyclic tensile strain on bone morphogenetic protein (BMP-2) mRNA expression," in Proceedings of the Tissue Engineering Workshop-The Next Generation, pp. 3459-3465, Mary Ann Liebert, 2006.

[42] D. F. Ward Jr., R. M. Salasznyk, R. F. Klees, et al., "Mechanical strain enhances extracellular matrix-induced gene focusing and promotes osteogenic differentiation of human mesenchymal stem cells through an extracellular-related kinasedependent pathway," Stem Cells and Development, vol. 16, no. 3, pp. 467-479, 2007.

[43] N. Datta, Q. P. Pham, U. Sharma, V. I. Sikavitsas, J. A. Jansen, and A. G. Mikos, "In vitro generated extracellular matrix and fluid shear stress synergistically enhance 3D osteoblastic differentiation," Proceedings of the National Academy of Sciences of the United States of America, vol. 103, no. 8, pp. 2488-2493, 2006.

[44] M. R. Kreke, L. A. Sharp, Y. Woo Lee, and A. S. Goldstein, "Effect of intermittent shear stress on mechanotransductive signaling and osteoblastic differentiation of bone marrow stromal cells," Tissue Engineering Part A, vol. 14, no. 4, pp. 529-537, 2008.

[45] L. A. Sharp, Y. W. Lee, and A. S. Goldstein, "Effect of low-frequency pulsatile flow on expression of osteoblastic genes by bone marrow stromal cells," Annals of Biomedical Engineering, vol. 37, no. 3, pp. 445-453, 2009.

[46] F. Zhao, R. Chella, and T. Ma, "Effects of shear stress on 3D human mesenchymal stem cell construct development in a perfusion bioreactor system: experiments and hydrodynamic modeling," Biotechnology and Bioengineering, vol. 96, no. 3, pp. 584-595, 2007.

[47] Y. J. Li, N. N. Batra, L. You, et al., "Oscillatory fluid flow affects human marrow stromal cell proliferation and differentiation," Journal of Orthopaedic Research, vol. 22, no. 6, pp. 1283-1289, 2004.

[48] K. Ebisawa, K. I. Hata, K. Okada, et al., "Ultrasound enhances transforming growth factor beta-mediated chondrocyte differentiation of human mesenchymal stem cells," in Proceedings of the 5th International Conference of the TissueEngineering-Society, pp. 921-929, Mary Ann Liebert, Kobe, Japan, 2002.

[49] H. J. Lee, B. H. Choi, B.-H. Min, Y. S. Son, and S. R. Park, "Low-intensity ultrasound stimulation enhances chondrogenic differentiation in alginate culture of mesenchymal stem cells," Artificial Organs, vol. 30, no. 9, pp. 707-715, 2006.
[50] A. K. Haudenschild, A. H. Hsieh, S. Kapila, and J. C. Lotz, "Pressure and distortion regulate human mesenchymal stem cell gene expression," Annals of Biomedical Engineering, vol. 37, no. 3, pp. 492-502, 2009.

[51] L. Khatib, D. E. Golan, and M. Cho, "Physiologic electrical stimulation provokes intracellular calcium increase mediated by phospholipase C activation in human osteoblasts," FASEB Journal, vol. 18, no. 15, pp. 1903-1905, 2004.

[52] C.-C. Wu, Y.-C. Chao, C.-N. Chen, et al., "Synergism of biochemical and mechanical stimuli in the differentiation of human placenta-derived multipotent cells into endothelial cells," Journal of Biomechanics, vol. 41, no. 4, pp. 813-821, 2008.

[53] K. Miyanishi, M. C. D. Trindade, D. P. Lindsey, et al., "Effects of hydrostatic pressure and transforming growth factor- $\beta 3$ on adult human mesenchymal stem cell chondrogenesis in vitro," Tissue Engineering, vol. 12, no. 6, pp. 1419-1428, 2006.

[54] H. L. Holtorf, J. A. Jansen, and A. G. Mikos, "Flow perfusion culture induces the osteoblastic differentiation of marrow stromal cell-scaffold constructs in the absence of dexamethasone," in Proceedings of the 7th World Biomaterials Congress, pp. 326-334, Wiley-Liss, Sydney, Australia, 2004.

[55] M. Jagodzinski, A. Breitbart, M. Wehmeier, et al., "Influence of perfusion and cyclic compression on proliferation and differentiation of bone marrow stromal cells in 3-dimensional culture," Journal of Biomechanics, vol. 41, no. 9, pp. 18851891, 2008.

[56] I. S. Kim, J. K. Song, Y. M. Song, et al., "Novel effect of biphasic electric current on in vitro osteogenesis and cytokine production in human mesenchymal stromal cells," Tissue Engineering Part A, vol. 15, no. 9, pp. 2411-2422, 2009.

[57] E. Bieberich and A. Guiseppi-Elie, "Neuronal differentiation and synapse formation of PC12 and embryonic stem cells on interdigitated microelectrode arrays: contact structures for neuron-to-electrode signal transmission (NEST)," Biosensors and Bioelectronics, vol. 19, no. 8, pp. 923-931, 2004.

[58] E. den Dekker, G. Gorter, H. van der Vuurst, J. W. M. Heemskerk, and J.-W. N. Akkerman, "Biogenesis of Gprotein mediated calcium signaling in human megakaryocytes," Thrombosis and Haemostasis, vol. 86, no. 4, pp. 11061113, 2001.

[59] S. J. A. D’Souza, A. Pajak, K. Balazsi, and L. Dagnino, " $\mathrm{Ca}^{2+}$ and BMP-6 signaling regulate E2F during epidermal keratinocyte differentiation," The Journal of Biological Chemistry, vol. 276, no. 26, pp. 23531-23538, 2001.

[60] N. C. Spitzer, C. M. Root, and L. N. Borodinsky, "Orchestrating neuronal differentiation: patterns of $\mathrm{Ca}^{2+}$ spikes specify transmitter choice," Trends in Neurosciences, vol. 27, no. 7, pp. 415-421, 2004.

[61] B. Binétruya, L. Heasley, F. Bost, L. Caron, and M. Aouadi, "Concise review: regulation of embryonic stem cell lineage commitment by mitogen-activated protein kinases," Stem Cells, vol. 25, no. 5, pp. 1090-1095, 2007.

[62] J. Liu, Z. Zhao, J. Li, et al., "Hydrostatic pressures promote initial osteodifferentiation with ERK1/2 not p38 MAPK signaling involved," Journal of Cellular Biochemistry, vol. 107, no. 2, pp. 224-232, 2009.

[63] I. Titushkin and M. Cho, "Modulation of cellular mechanics during osteogenic differentiation of human mesenchymal stem cells," Biophysical Journal, vol. 93, no. 10, pp. 36933702, 2007.

[64] M. J. Berridge, M. D. Bootman, and H. L. Roderick, "Calcium signalling: dynamics, homeostasis and remodelling," Nature 
Reviews Molecular Cell Biology, vol. 4, no. 7, pp. 517-529, 2003.

[65] P. Lory, I. Bidaud, and J. Chemin, "T-type calcium channels in differentiation and proliferation," Cell Calcium, vol. 40, no. 2, pp. 135-146, 2006.

[66] M. A. Foreman, J. Smith, and S. J. Publicover, "Characterisation of serum-induced intracellular $\mathrm{Ca}^{2+}$ oscillations in primary bone marrow stromal cells," Journal of Cellular Physiology, vol. 206, no. 3, pp. 664-671, 2006.

[67] T. Nevian and B. Sakmann, "Spine $\mathrm{Ca}^{2+}$ signaling in spiketiming-dependent plasticity," Journal of Neuroscience, vol. 26, no. 43, pp. 11001-11013, 2006.

[68] S. Kawano, K. Otsu, A. Kuruma, et al., "ATP autocrine/ paracrine signaling induces calcium oscillations and NFAT activation in human mesenchymal stem cells," Cell Calcium, vol. 39, no. 4, pp. 313-324, 2006.

[69] C. Guibert, T. Ducret, and J.-P. Savineau, "Voltageindependent calcium influx in smooth muscle," Progress in Biophysics and Molecular Biology, vol. 98, no. 1, pp. 10-23, 2008.

[70] C. G. Mohan and T. Gandhi, "Therapeutic potential of voltage gated calcium channels," Mini-Reviews in Medicinal Chemistry, vol. 8, no. 12, pp. 1285-1290, 2008.

[71] A. J. Williams, D. J. West, and R. Sitsapesan, "Light at the end of the $\mathrm{Ca}^{2+}$-release channel tunnel: structures and mechanisms involved in ion translocation in ryanodine receptor channels," Quarterly Reviews of Biophysics, vol. 34, no. 1, pp. 61-104, 2001.

[72] A. Hovnanian, "SERCA pumps and human diseases," SubCellular Biochemistry, vol. 45, pp. 337-363, 2007.

[73] T.-J. Kim, J. Seong, M. Ouyang, et al., "Substrate rigidity regulates $\mathrm{Ca}^{2+}$ oscillation via RhoA pathway in stem cells," Journal of Cellular Physiology, vol. 218, no. 2, pp. 285-293, 2009.

[74] S. Kawano, K. Otsu, S. Shoji, K. Yamagata, and M. Hiraoka, " $\mathrm{Ca}^{2+}$ oscillations regulated by $\mathrm{Na}^{+}-\mathrm{Ca}^{2+}$ exchanger and plasma membrane $\mathrm{Ca}^{2+}$ pump induce fluctuations of membrane currents and potentials in human mesenchymal stem cells," Cell Calcium, vol. 34, no. 2, pp. 145-156, 2003.

[75] R. C. Riddle, A. F. Taylor, D. C. Genetos, and H. J. Donahue, "MAP kinase and calcium signaling mediate fluid flow-induced human mesenchymal stem cell proliferation," American Journal of Physiology, vol. 290, no. 3, pp. C776C784, 2006.

[76] M. D. Sjaastad and W. J. Nelson, "Integrin-mediated calcium signaling and regulation of cell adhesion by intracellular calcium," BioEssays, vol. 19, no. 1, pp. 47-55, 1997.

[77] G. Giannone, P. Ronde, M. Gaire, J. Haiech, and K. Takeda, "Calcium oscillations trigger focal adhesion disassembly in human U87 astrocytoma cells," The Journal of Biological Chemistry, vol. 277, no. 29, pp. 26364-26371, 2002.

[78] K. Montzka, N. Lassonczyk, B. Tschöke, et al., "Neural differentiation potential of human bone marrow-derived mesenchymal stromal cells: misleading marker gene expression," BMC Neuroscience, vol. 10, article 16, 2009.

[79] M. Dezawa, "Systematic neuronal and muscle induction systems in bone marrow stromal cells: the potential for tissue reconstruction in neurodegenerative and muscle degenerative diseases," Medical Molecular Morphology, vol. 41, no. 1, pp. 14-19, 2008.

[80] S. Song and J. Sanchez-Ramos, "Preparation of neural progenitors from bone marrow and umbilical cord blood," Methods in Molecular Biology, vol. 438, pp. 123-134, 2008.
[81] J. Sanchez-Ramos, S. Song, F. Cardozo-Pelaez, et al., "Adult bone marrow stromal cells differentiate into neural cells in vitro," Experimental Neurology, vol. 164, no. 2, pp. 247-256, 2000.

[82] A. Hermann, S. Liebau, R. Gastl, et al., "Comparative analysis of neuroectodermal differentiation capacity of human bone marrow stromal cells using various conversion protocols," Journal of Neuroscience Research, vol. 83, no. 8, pp. 15021514, 2006.

[83] B. Neuhuber, G. Gallo, L. Howard, L. Kostura, A. Mackay, and I. Fischer, "Reevaluation of in vitro differentiation protocols for bone marrow stromal cells: disruption of actin cytoskeleton induces rapid morphological changes and mimics neuronal phenotype," Journal of Neuroscience Research, vol. 77, no. 2, pp. 192-204, 2004.

[84] P. Lu, A. Blesch, and M. H. Tuszynski, "Induction of bone marrow stromal cells to neurons: differentiation, transdifferentiation, or artifact?" Journal of Neuroscience Research, vol. 77, no. 2, pp. 174-191, 2004.

[85] D. Woodbury, E. J. Schwarz, D. J. Prockop, and I. B. Black, "Adult rat and human bone marrow stromal cells differentiate into neurons," Journal of Neuroscience Research, vol. 61, no. 4, pp. 364-370, 2000.

[86] V. S. Rao, I. A. Titushkin, E. G. Moros, W. F. Pickard, H. S. Thatte, and M. R. Cho, "Nonthermal effects of radiofrequency-field exposure on calcium dynamics in stem cell-derived neuronal cells: elucidation of calcium pathways," Radiation Research, vol. 169, no. 3, pp. 319-329, 2008.

[87] S. W. Martin, A. J. Butcher, N. S. Berrow, et al., "Phosphorylation sites on calcium channel $\alpha 1$ and $\beta$ subunits regulate ERK-dependent modulation of neuronal N-type calcium channels," Cell Calcium, vol. 39, no. 3, pp. 275-292, 2006.

[88] N. Morino, T. Mimura, K. Hamasaki, et al., "Matrix/integrin interaction activates the mitogen-activated protein kinase, $\mathrm{p} 44^{\text {erk-1 }}$ and $\mathrm{p} 42^{\text {erk-2 }}$," The Journal of Biological Chemistry, vol. 270, no. 1, pp. 269-273, 1995.

[89] T. Burdon, A. Smith, and P. Savatier, "Signalling, cell cycle and pluripotency in embryonic stem cells," Trends in Cell Biology, vol. 12, no. 9, pp. 432-438, 2002.

[90] D. Gioeli, J. W. Mandell, G. R. Petroni, H. F. Frierson Jr., and M. J. Weber, "Activation of mitogen-activated protein kinase associated with prostate cancer progression," Cancer Research, vol. 59, no. 2, pp. 279-284, 1999.

[91] R. Hoshino, Y. Chatani, T. Yamori, et al., "Constitutive activation of the $41-/ 43-\mathrm{kDa}$ mitogen-activated protein kinase signaling pathway in human tumors," Oncogene, vol. 18, no. 3, pp. 813-822, 1999.

[92] J. W. Mandell, I. M. Hussaini, M. Zecevic, M. J. Weber, and S. R. VandenBerg, "In situ visualization of intratumor growth factor signaling: immunohistochemical localization of activated ERK/MAP kinase in glial neoplasms," American Journal of Pathology, vol. 153, no. 5, pp. 1411-1423, 1998.

[93] H. L Jessop, S. C. F Rawlinson, A. A Pitsillides, and L. E Lanyon, "Mechanical strain and fluid movement both activate extracellular regulated kinase (ERK) in osteoblastlike cells but via different signaling pathways," Bone, vol. 31, no. 1, pp. 186-194, 2002.

[94] M. Kohno and J. Pouyssegur, "Pharmacological inhibitors of the ERK signaling pathway: application as anticancer drugs," Progress in Cell Cycle Research, vol. 5, pp. 219-224, 2003.

[95] T. S. Lewis, P. S. Shapiro, and N. G. Ahn, "Signal transduction through MAP kinase cascades," Advances in Cancer Research, vol. 74, pp. 137-139, 1998. 
[96] G. Pearson, F. Robinson, T. B. Gibson, et al., "Mitogenactivated protein (MAP) kinase pathways: regulation and physiological functions," Endocrine Reviews, vol. 22, no. 2, pp. 153-183, 2001.

[97] R. Seger and E. G. Krebs, "The MAPK signaling cascade," FASEB Journal, vol. 9, no. 9, pp. 726-735, 1995.

[98] B. Su and M. Karin, "Mitogen-activated protein kinase cascades and regulation of gene expression," Current Opinion in Immunology, vol. 8, no. 3, pp. 402-411, 1996.

[99] R. J. Davis, “MAPKs: new JNK expands the group," Trends in Biochemical Sciences, vol. 19, no. 11, pp. 470-473, 1994.

[100] C. A. Simmons, S. Matlis, A. J. Thornton, S. Chen, C.-Y. Wang, and D. J. Mooney, "Cyclic strain enhances matrix mineralization by adult human mesenchymal stem cells via the extracellular signal-regulated kinase (ERK1/2) signaling pathway," Journal of Biomechanics, vol. 36, no. 8, pp. 10871096, 2003.

[101] J. You, G. C. Reilly, X. Zhen, et al., "Osteopontin gene regulation by oscillatory fluid flow via intracellular calcium mobilization and activation of mitogen-activated protein kinase in MC3T3-E1 osteoblasts," The Journal of Biological Chemistry, vol. 276, no. 16, pp. 13365-13371, 2001.

[102] E. Hentzen, D. McDonough, L. McIntire, C. W. Smith, H. L. Goldsmith, and S. I. Simon, "Hydrodynamic shear and tethering through E-selectin signals phosphorylation of p38 MAP kinase and adhesion of human neutrophils," Annals of Biomedical Engineering, vol. 30, no. 8, pp. 987-1001, 2002.

[103] K.-D. Chen, Y.-S. Li, M. Kim, et al., "Mechanotransduction in response to shear stress. Roles of receptor tyrosine kinases, integrins, and Shc," The Journal of Biological Chemistry, vol. 274, no. 26, pp. 18393-18400, 1999.

[104] E. Puklin-Faucher and M. P. Sheetz, "The mechanical integrin cycle," Journal of Cell Science, vol. 122, no. 2, pp. 179186, 2009.

[105] Y. Wang, L. M. McNamara, M. B. Schaffler, and S. Weinbaum, "A model for the role of integrins in flow induced mechanotransduction in osteocytes," Proceedings of the National Academy of Sciences of the United States of America, vol. 104, no. 40, pp. 15941-15946, 2007.

[106] B. D. Matthews, D. R. Overby, R. Mannix, and D. E. Ingber, "Cellular adaptation to mechanical stress: role of integrins, Rho, cytoskeletal tension and mechanosensitive ion channels," Journal of Cell Science, vol. 119, no. 3, pp. 508518, 2006.

[107] M. A. Schwartz and D. W. DeSimone, "Cell adhesion receptors in mechanotransduction," Current Opinion in Cell Biology, vol. 20, no. 5, pp. 551-556, 2008.

[108] D. E. Ingber, "Cellular mechanotransduction: putting all the pieces together again," FASEB Journal, vol. 20, no. 7, pp. 811$827,2006$.

[109] B. D. Matthews, C. K. Thodeti, and D. E. Ingber, "Activation of mechanosensitive ion channels by forces transmitted through integrins and the cytoskeleton," Current Topics in Membranes, vol. 58, pp. 59-85, 2007.

[110] M. R. Cho, H. S. Thatte, R. C. Lee, and D. E. Golan, "Integrin-dependent human macrophage migration induced by oscillatory electrical stimulation," Annals of Biomedical Engineering, vol. 28, no. 3, pp. 234-243, 2000.

[111] S. Sun and M. Cho, "Human fibroblast migration in threedimensional collagen gel in response to noninvasive electrical stimulus: II. Identification of electrocoupling molecular mechanisms," Tissue Engineering, vol. 10, no. 9-10, pp. 1558$1565,2004$.
[112] R. O. Hynes, "Integrins: versatility, modulation, and signaling in cell adhesion," Cell, vol. 69, no. 1, pp. 11-25, 1992.

[113] M. C. Tate, A. J. García, B. G. Keselowsky, M. A. Schumm, D. R. Archer, and M. C. Laplaca, "Specific $\beta_{1}$ integrins mediate adhesion, migration, and differentiation of neural progenitors derived from the embryonic striatum," Molecular and Cellular Neuroscience, vol. 27, no. 1, pp. 22-31, 2004.

[114] A. G. Arroyo, J. T. Yang, H. Rayburn, and R. O. Hynes, “ $\alpha_{4}$ integrins regulate the proliferation/differentiation balance of multilineage hematopoietic progenitors in vivo," Immunity, vol. 11, no. 5, pp. 555-566, 1999.

[115] N. Maitra, I. L. Flink, J. J. Bahl, and E. Morkin, "Expression of $\alpha$ and $\beta$ integrins during terminal differentiation of cardiomyocytes," Cardiovascular Research, vol. 47, no. 4, pp. 715-725, 2000.

[116] N. Yoshida, S. Hishiyama, M. Yamaguchi, et al., "Decrease in expression of $\alpha_{5} \beta_{1}$ integrin during neuronal differentiation of cortical progenitor cells," Experimental Cell Research, vol. 287, no. 2, pp. 262-271, 2003.

[117] J. H Bennett, D. H. Carter, A. L. Alavi, J. N. Beresford, and S. Walsh, "Patterns of integrin expression in a human mandibular explant model of osteoblast differentiation," Archives of Oral Biology, vol. 46, no. 3, pp. 229-238, 2001.

[118] K. M. Yamada and S. Even-Ram, "Integrin regulation of growth factor receptors," Nature Cell Biology, vol. 4, no. 4, pp. E75-E76, 2002.

[119] M. A. Lopez-Toledano, C. Redondo, M. V. T. Lobo, et al., "Tyrosine hydroxylase induction by basic fibroblast growth factor and cyclic AMP analogs in striatal neural stem cells: role of ERK1/ERK2 mitogen-activated protein kinase and protein kinase C," Journal of Histochemistry and Cytochemistry, vol. 52, no. 9, pp. 1177-1189, 2004.

[120] P. J. Marie, "Fibroblast growth factor signaling controlling osteoblast differentiation," Gene, vol. 316, no. 1-2, pp. 23-32, 2003.

[121] M. R. Cho, "A review of electrocoupling mechanisms mediating facilitated wound healing," IEEE Transactions on Plasma Science, vol. 30, no. 4, pp. 1504-1515, 2003.

[122] M. A. Wozniak, K. Modzelewska, L. Kwong, and P. J. Keely, "Focal adhesion regulation of cell behavior," Biochimica et Biophysica Acta, vol. 1692, no. 2-3, pp. 103-119, 2004.

[123] C. K. Miranti and J. S. Brugge, "Sensing the environment: a historical perspective on integrin signal transduction," Nature Cell Biology, vol. 4, no. 4, pp. E83-E90, 2002.

[124] C. S. Chen, "Mechanotransduction-a field pulling together?" Journal of Cell Science, vol. 121, no. 20, pp. 3285-3292, 2008.

[125] M. A. Schwartz, "Cell biology: the force is with us," Science, vol. 323, no. 5914, pp. 588-589, 2009.

[126] N. Wang, J. D. Tytell, and D. E. Ingber, "Mechanotransduction at a distance: mechanically coupling the extracellular matrix with the nucleus," Nature Reviews Molecular Cell Biology, vol. 10, no. 1, pp. 75-82, 2009.

[127] P. A. Janmey and C. A. McCulloch, "Cell mechanics: integrating cell responses to mechanical stimuli," Annual Review of Biomedical Engineering, vol. 9, pp. 1-34, 2007.

[128] C. T. Lim, E. H. Zhou, and S. T. Quek, "Mechanical models for living cells—a review," Journal of Biomechanics, vol. 39, no. 2, pp. 195-216, 2006.

[129] A. W. Orr, B. P. Helmke, B. R. Blackman, and M. A. Schwartz, "Mechanisms of mechanotransduction," Developmental Cell, vol. 10, no. 1, pp. 11-20, 2006. 
[130] J. H.-C. Wang, B. P. Thampatty, J.-S. Lin, and H.-J. Im, "Mechanoregulation of gene expression in fibroblasts," Gene, vol. 391, no. 1-2, pp. 1-15, 2007.

[131] B. P. Jena, "Secretion machinery at the cell plasma membrane," Current Opinion in Structural Biology, vol. 17, no. 4, pp. 437-443, 2007.

[132] C. E. Morris and U. Homann, "Cell surface area regulation and membrane tension," Journal of Membrane Biology, vol. 179, no. 2, pp. 79-102, 2001.

[133] D. Raucher and M. P. Sheetz, "Characteristics of a membrane reservoir buffering membrane tension," Biophysical Journal, vol. 77, no. 4, pp. 1992-2002, 1999.

[134] M. Sun, N. Northup, F. Marga, et al., "The effect of cellular cholesterol on membrane-cytoskeleton adhesion," Journal of Cell Science, vol. 120, no. 13, pp. 2223-2231, 2007.

[135] M. P. Sheetz, J. E. Sable, and H.-G. Döbereiner, "Continuous membrane-cytoskeleton adhesion requires continuous accommodation to lipid and cytoskeleton dynamics," Annual Review of Biophysics and Biomolecular Structure, vol. 35, pp. 417-434, 2006.

[136] I. Titushkin and M. Cho, "Distinct membrane mechanical properties of human mesenchymal stem cells determined using laser optical tweezers," Biophysical Journal, vol. 90, no. 7, pp. 2582-2591, 2006.

[137] O. Barreiro, M. Yanez-Mo, J. M. Serrador, et al., "Dynamic interaction of VCAM-1 and ICAM-1 with moesin and ezrin in a novel endothelial docking structure for adherent leukocytes," Journal of Cell Biology, vol. 157, no. 7, pp. 12331245, 2002.

[138] A. Bretscher, "Regulation of cortical structure by the ezrinradixin-moesin protein family," Current Opinion in Cell Biology, vol. 11, no. 1, pp. 109-116, 1999.

[139] S. Louvet-Vallee, "ERM proteins: from cellular architecture to cell signaling," Biology of the Cell, vol. 92, no. 5, pp. 305$316,2000$.

[140] P. Mangeat, C. Roy, and M. Martin, "ERM proteins in cell adhesion and membrane dynamics," Trends in Cell Biology, vol. 9, no. 5, pp. 187-192, 1999.

[141] S. Tsukita and S. Yonemura, "Cortical actin organization: lessons from ERM (ezrin/radixin/moesin) proteins," The Journal of Biological Chemistry, vol. 274, no. 49, pp. 3450734510, 1999.

[142] R. J. Shaw, M. Henry, F. Solomon, and T. Jacks, "RhoAdependent phosphorylation and relocalization of ERM proteins into apical membrane/actin protrusions in fibroblasts," Molecular Biology of the Cell, vol. 9, no. 2, pp. 403-419, 1998.

[143] Y. Luo, X. Xu, T. Lele, S. Kumar, and D. E. Ingber, "A multimodular tensegrity model of an actin stress fiber," Journal of Biomechanics, vol. 41, no. 11, pp. 2379-2387, 2008.

[144] B. D. Matthews, D. R. Overby, R. Mannix, and D. E. Ingber, "Cellular adaptation to mechanical stress: role of integrins, Rho, cytoskeletal tension and mechanosensitive ion channels," Journal of Cell Science, vol. 119, no. 3, pp. 508$518,2006$.

[145] Z. Mostafavi-Pour, J. A. Askari, S. J. Parkinson, P. J. Parker, T. T. C. Ng, and M. J. Humphries, "Integrin-specific signaling pathways controlling focal adhesion formation and cell migration," Journal of Cell Biology, vol. 161, no. 1, pp. 155$167,2003$.

[146] L. A. McMahon, V. A. Campbell, and P. J. Prendergast, "Involvement of stretch-activated ion channels in strainregulated glycosaminoglycan synthesis in mesenchymal stem cell-seeded 3D scaffolds," Journal of Biomechanics, vol. 41, no. 9, pp. 2055-2059, 2008.
[147] J. K. Mouw, S. M. Imler, and M. E. Levenston, "Ion-channel regulation of chondrocyte matrix synthesis in 3D culture under static and dynamic compression," Biomechanics and Modeling in Mechanobiology, vol. 6, no. 1-2, pp. 33-41, 2007.

[148] H. Chen, I. Titushkin, M. Stroscio, and M. Cho, "Altered membrane dynamics of quantum dot-conjugated integrins during osteogenic differentiation of human bone marrow derived progenitor cells," Biophysical Journal, vol. 92, no. 4, pp. 1399-1408, 2007.

[149] J. Dai, M. P. Sheetz, X. Wan, and C. E. Morris, "Membrane tension in swelling and shrinking molluscan neurons," Journal of Neuroscience, vol. 18, no. 17, pp. 6681-6692, 1998.

[150] G. E. P. Box, J. S. Hunter, and W. G. Hunter, Statistics fro Experimenters: Design, Innovation, and Discovery, WileyInterscience, Hoboken, NJ, USA, 2nd edition, 2005. 

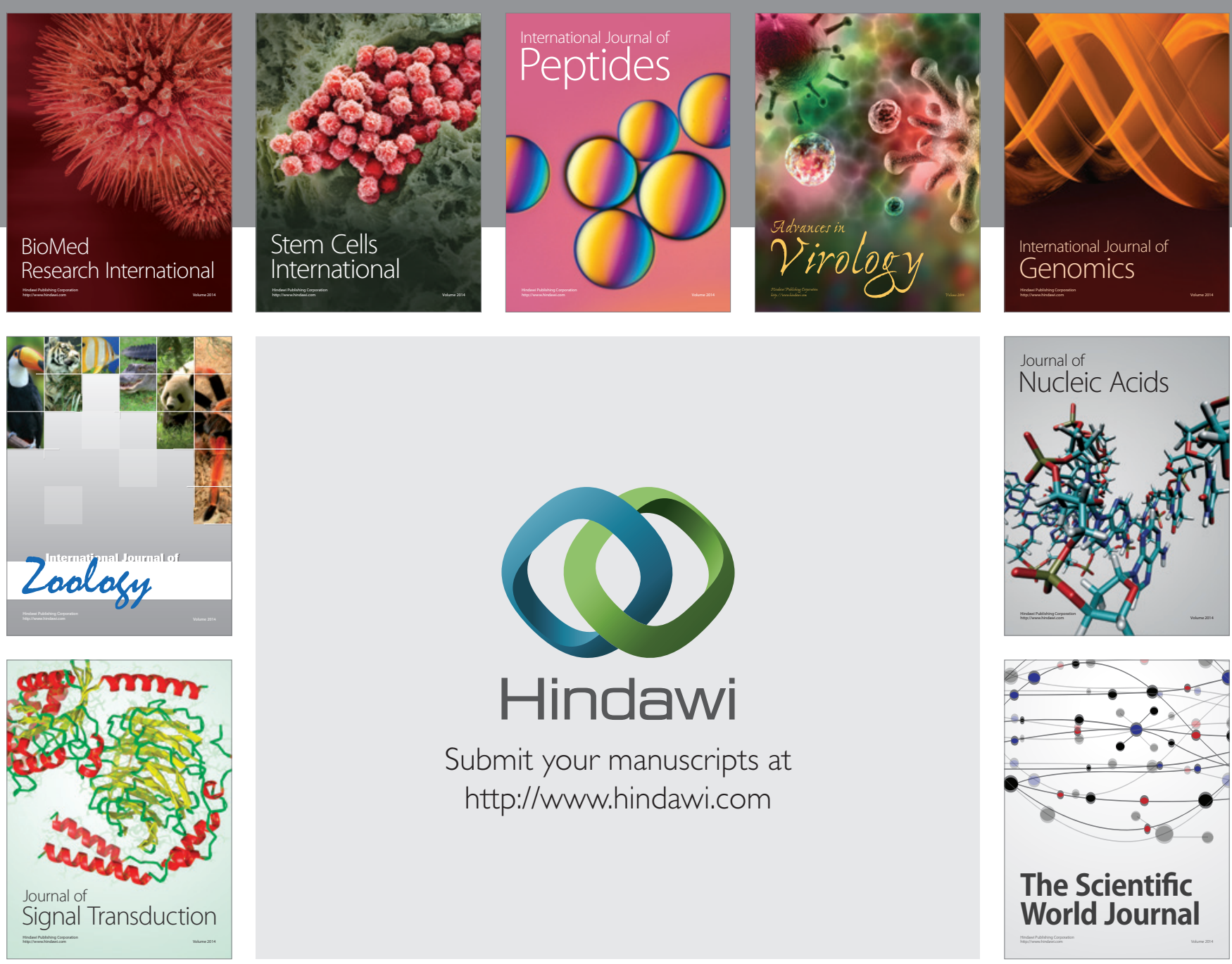

Submit your manuscripts at

http://www.hindawi.com
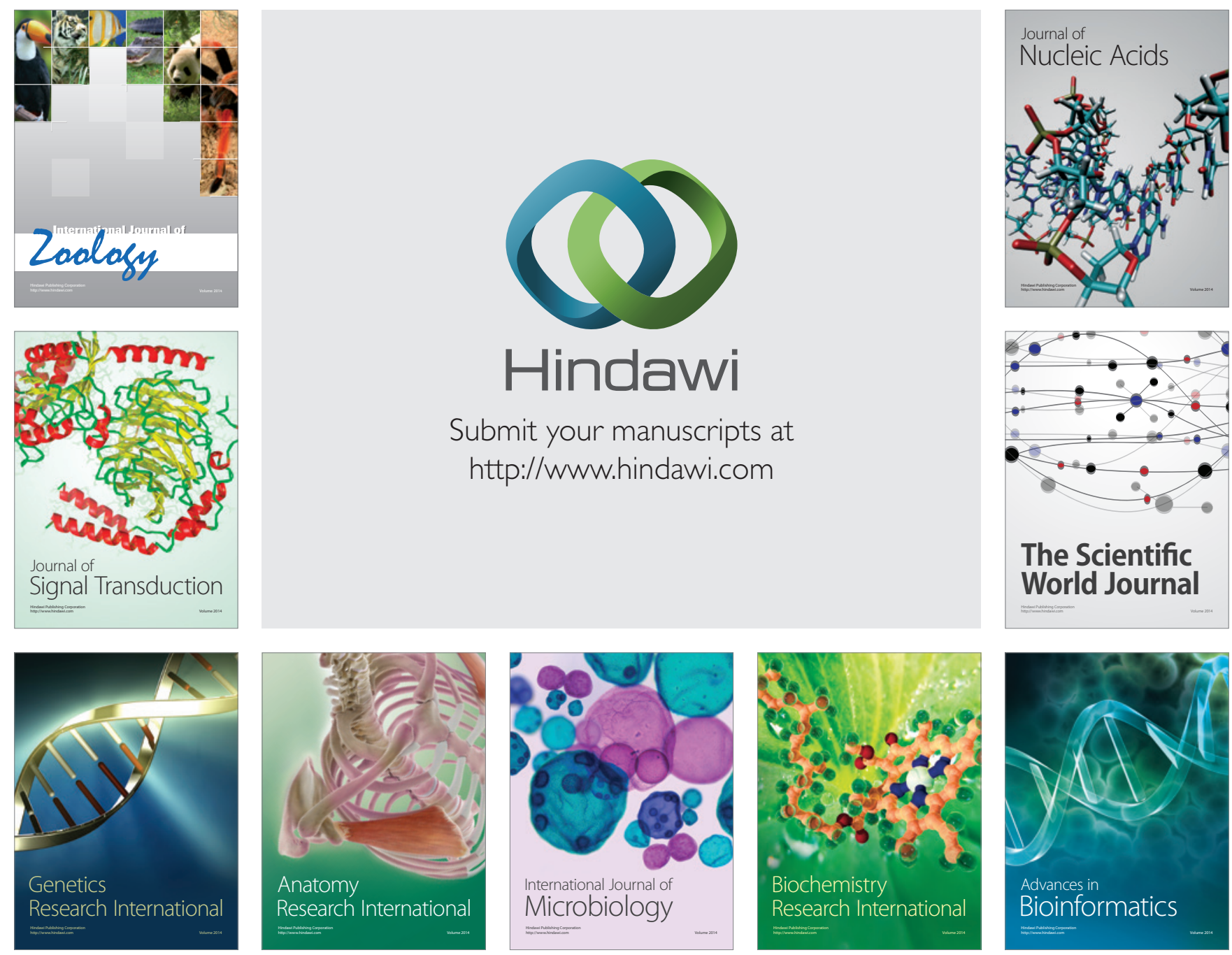

The Scientific World Journal
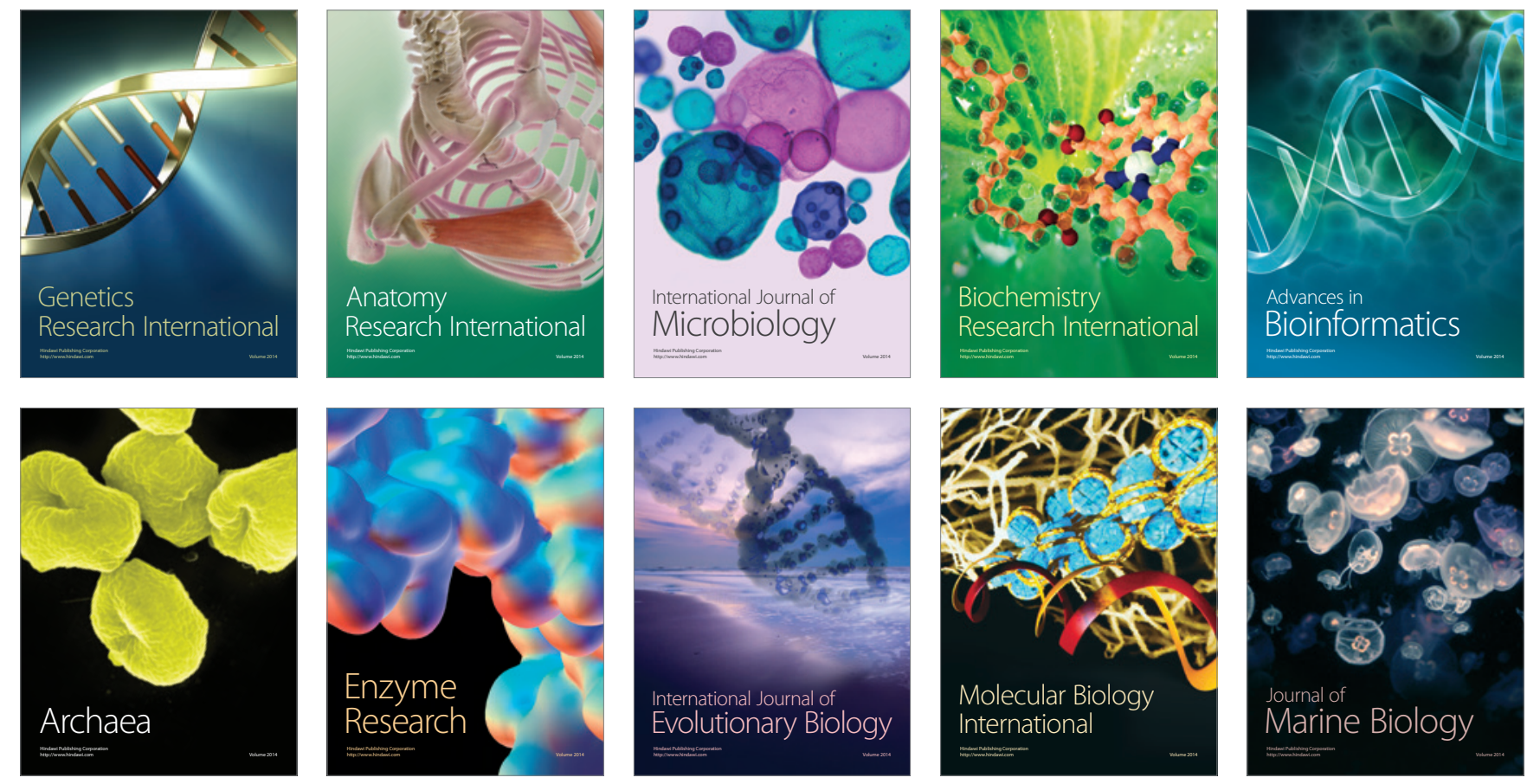